\title{
THE METAPHYSICS OF $\mathrm{A}$
}

NATURALIST

0. 1., INRTCH 


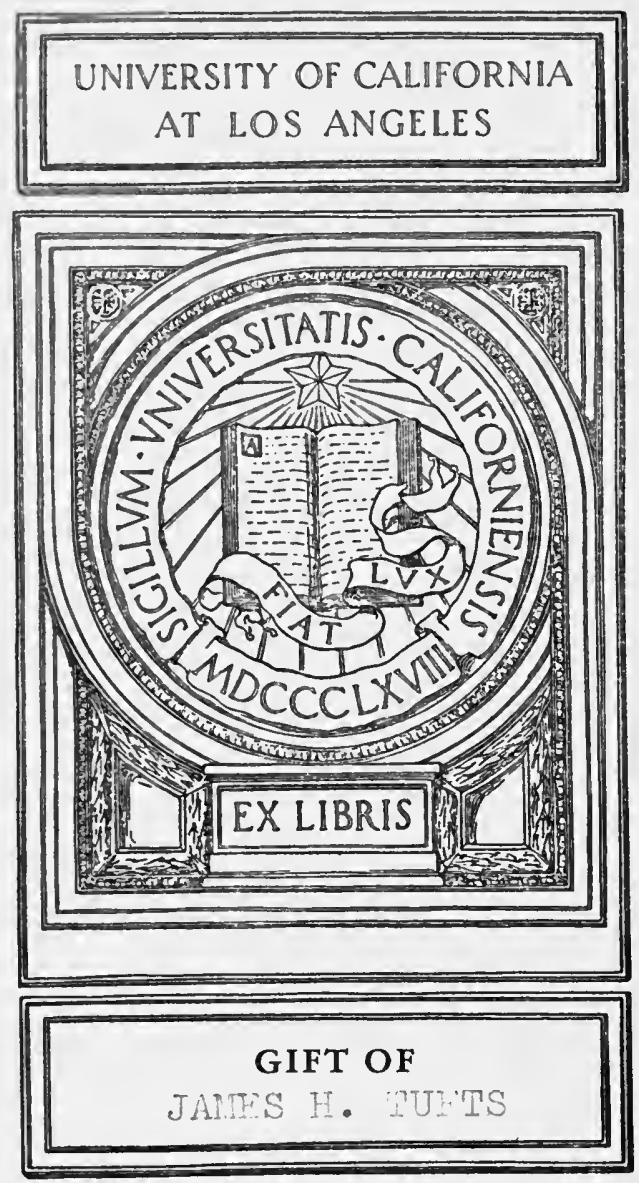






\section{Digitized by the Internet Archive in 2007 with funding from Microsoft Corporation}




\section{CLARENGE LUTHER HERRICK}

1858

1904

\section{FOUNDER OF THE}

DENISON SCIENTIFIC ASSDGIATION

BULLETIN OF THE SCIENTIFIC

LABORATORIES

JBURNAL OF COMPARATIVE NEUROLOCY

$$
\text { A TRUE TEACHER }
$$

MEMORIAL TABLET

UNVEILED IN BARNEY MEMORIAL SCIENCE HALL, NOVEMBER, 1908 


\title{
BULLETIN
}

OP THE

\section{SCIENTIFIC LABORATORIES}

OF

\section{DENISON UNIVERSITY}

\author{
EDITED BY \\ FRANK CARNEY \\ Permanent Secretary Denison Scientific Association
}

This volume is published in commemoration of the twenty-fifth anniversary of the election of Clarence Luther Herrick to the Professorship of

Geology and Natural History at Denison University

$$
\text { VOL. XV }
$$

GRANVILLE, OHIO, 1910 


\section{•}

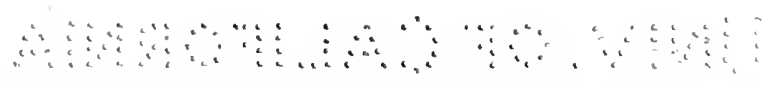

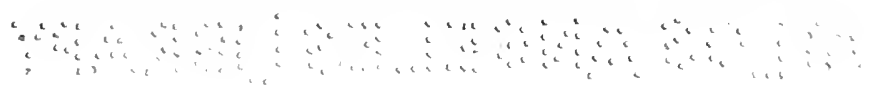




\title{
The
}

METAPHYSICS of a NATURALIST

\author{
PHILOSOPHICAL AND PSYCHOLOGICAL
}

FRAGMENTS

BY THE LATE

C. L. HERRICK 


\section{CONTENTS}

Introluction......................................... 1

The Summation-Irradiation Theory of Pleasure-Pain.............. 5

The Equilibrium Theory of Consciousness. . . . . . . . . . . . . . . . 12

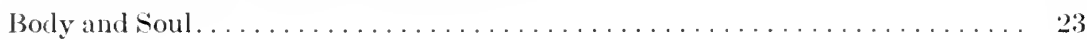

$\stackrel{\oplus}{\mathscr{m}}$

The Concept of Individuality . . . . . . . . . . . . . . . . . . . 29

The Fundamental Postulate of Dynamic Monism................. 39

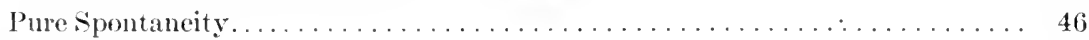

* Historical Set ting. . . . . . . . . . . . . . . . . . . . . . 49

$>$ Energism: Thr Fundamental Prineiples of Dynamic Realism . . . . . . . . 52

$\sum$ The Postulate of Resistance . . . . . . . . . . . . . . . . . . . . . . 59

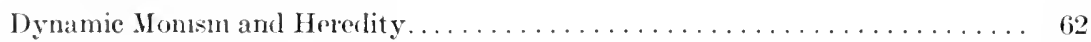

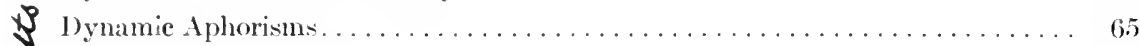

5 The Fredom of the Will. . . . . . .

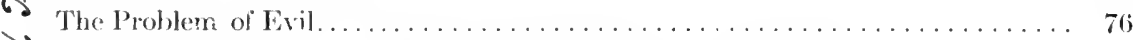

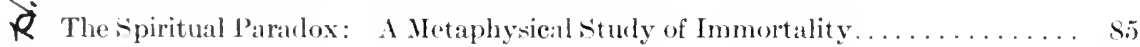

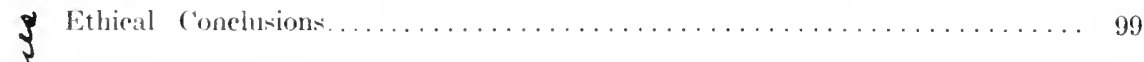


$$
\text { . }
$$

- 


\title{
THE METAPHYSICS OF A NATURALIST
}

\author{
Philosophical and Psychological Fragments by the \\ Late C. L. Herrick
}

\section{INTRODUCTION}

In these days when philosophy is considered less and less as transcendental metaphysies and more and more in terms of the instrumental methodology of the sciences, the thoughts and writings of men who represent this phase of human endeavor are eoming to be valued above every other source of philosophieal inspiration, The opinions of such men as Tyndall, Huxley, Helmholtz, Kelvin, Mach, Ostwald, to mention no others, become of great significanee to philosophy when the latter is conceived as an interpretation and critieism of the underlying prineiples and methods of the seienees.

It is as a contribution to this increasingly valuable literature that these pages are offered to the public. Professor Herrick was not only an eminent naturalist and neurologist, but from the first he conceived and executed his researches in a philosophie spirit and with the special problems of psychology in mind. This fact in itself would make his views of interest. But when to this the fact is added that his ideas are always expressed vivaciously and in suggestive form, his writings become doubly interesting and important.

An account of the life and work of Prof. Clarence Luther Herrick, with portrait and an appended bibliography, may be found in the Journal of Comparative Neurology and Psychology and more fully in the Bulletin of the Scientific Laboratories of Denison University. ${ }^{2}$ As a young man, while serving on the Geological and Natural History Survey of Minnesota, he acquired a thorough and broad knowledge of natural history, devoting himself to paleontology, systematie zoölogy and comparative anat-

'Vol. 14, no. 6. November, 1904.

${ }^{2}$ Vol. 1:3, pp. 1 to 33. January, 1905. 
omy. The suceeding five years were devoted chiefly to geology, and the later years of his life to neurology, comparative psychology and philosophy. At the beginning of the latter period he founded in 1891 the Journal of Comparative Neurology and Psychology, which he continued to edit until his death. His interest in philosophical questions was perennially active, as shown by the note-books which he made as a college student, his correspondence throughout life, and his frequent contributions to the psychological and philosophical serials.

Professor Herrick, though a great admirer of Lotze, whose lectures on psychology he translated and privately printed while still a young man for the use of his classes (with, significantly, an appended chapter on the structure of the brain), ${ }^{3}$ was a disciple of no school. The systematist, he remarks in the introduction to one of his unpublished works, may be horrified to observe that questions of psychology and of neurology jostle problems of ontology and "Erkenntnistheorie." The hysterical individual, on the other hand, who finds the word system insupportable, will doubtless do well to stop here and may as well detain his fellow who sees in an unclassified fact a maverick escaped from the herd to be roped, rounded up and branded Hegelian, Herbartian, etc., as soon as possible.

The pages which follow were assembled shortly after Professor Herrick's death in 1904 from a large collection of miscellaneous papers. The greater part of this compilation was done by Prof. $H$. Heath Bawden, an arduous labor, very skillfully and sympathetically performed as a tribute from a pupil to the memory of his first master. The entire manuscript has been critically read by Dr. George Fitch McKibben whose association with Professor Herrick began when they were students in Germany.

The attempt has been made to correlate the most distinctive of the philosophical and psychological teachings of Professor Herrick by bringing together the important ideas scattered throughout his published writings and contained in hitherto inaccessible papers and unpublished manuscripts which it has been our privilege to consult. The greater part of what here appears is published for the first time, references being made to his published writings only so far as has been necessary to give the proper

${ }^{3}$ Puhlished at Minneapolis. Pp. $x+150,2$ plates, 1888. 
setting to this new material. The section on the theory of pleasure-pain alone contains any considerable amount of previously published matter and this is presented first in order to illustrate the nature of the data upon the basis of which the theory of consciousness and some other philosophical sections were elaborated. The chapters which are here assembled were not, however, prepared by the author with reference to each other, and this accounts for the large amount of repetition, which the editors have not attempted to eliminate.

A certain amount of interpretation and evaluation has been inevitable because of the fragmentary character of much of the material and because of the unelaborated state of many of the ideas themselves. But it has been the aim as far as possible to let Professor Herrick speak for himself.

In explanation of the heterogeneity and very unequal value of these chapters, attention should again be called to the fact that no one of them represents a finished product, and the parts were written at widely different times under exceedingly various conditions. Some of the most valuable passages have been extracted from personal letters. Others are taken from fragmentary pencil notes made when he was too ill to write more than a few minutes at a time. Some are sections extracted from partially elaborated drafts of systematic treatises. His papers contain outlines of four such books. Parts of two of these were quite fully written up; but very little of the others had been written.

He had in preparation a philosophical treatise and published some extracts from this work in the philosophical serials shortly before his death; others were published immediately thereafter. The earlier chapters of the present volume (except the first) have been drawn largely from the unpublished materials for this work. The later chapters are assembled for the most part from the notes for a text-book on ethics, to be entitled, Lectures on Conduct: The Principles of Ethics from the Dynamic Point of View.

These fragments suffer, not only from their hasty preparation and lack of revision, but also from the absence of the setting within which they were elaborated in the author's mind. Doubtless in the light of current criticism many details of psychological or philosophical exposition would be stated differently by the author if he were writing today. But the value of these papers 
is quite independent of these considerations; it lies rather in the insight given into the workings of a philosophically acute mind unusually richly furnished with the concrete data of scientific observation.

In $1885 \mathrm{Mr}$. Herrick was elected Professor of Geology and Natural History in Denison University, and in the course of the year following this appointment he founded the Denison Scientific Association and established the Bulletin of the Scientific Laboratories of Denison University as the organ of publication of this association and the exponent of the scientific life of the college. On this, the twenty-fifth anniversary of his professorship, the Denison Scientific Association sends forth this volume, containing some of the fruits of Professor Herrick's ripest thinking, in the belief that by the dissemination of his own words it can best honor the memory of its founder.

The Editors. 


\section{THE SUMMATION-IRRADIATION THEORY OF PLEASURE-PAIN}

Professor Herrick's theory of pleasure-pain is significant in that it states the physiological mechanism of tension and readjustment which are required by the James-Lange theory of emotion, especially in its revised form as stated by Professor Dewey and Professor Fite. ${ }^{4}$

There is no separate apparatus for feeling. With each act of the conscious organism there are changes of tone comparable to the accessory vibrations constituting the timber of a musical instrument. These are associated with vascular changes (variation in the pressure of the blood in the capillaries and probably in the brain). The disturbance of equilibrium in these and other ways produces the change in feeling tone, varying from mere somatic feeling to the explosive excitement of certain sense irradiations.

All sensations are experienced as pleasurable in proportion as they relieve existing strain or overcome resistance; as painful in proportion as they fail to relieve such strain or overcome accumulated resistance. In other words, pain means congestion, contraction, obstruction, disadaptation, a disproportionateness of stimulus to the conveying power of the organ. Pleasure means diffusion, expansion, irradiation, discharge. In both cases there is summation of stimuli, but in the case of pain this summation finds no overflow or discharge, or the process of inhibition is carried to the point where the subsequent discharge results in a further mal-adjustment.

"Often an interval of one or two seconds may elapse after the sensation is perceived before pain appears. These cases, so often quoted as proving the distinct nature of pain, are in one respect fallacious. When a nerve fiber is penetrated by a pin the pain is nearly, if not quite, as promptly felt as the touch. When the finger is struck by a hammer the pain is frequently long delayed. But the acme of pain in that case is

Cf. James, Psychology, vol. 2, p. 451; Psychological Review, vol. 1, 1894, p. 516; Fite, Psychological Review, vol. 10, 1903, p. 639; M'Lennan, Psychological Review, vol. 2,1895, p. 466. 
due to a reactionary process in the tissues, notably the vascular contractions. There may be several oscillations of pain and a set of summations of a curious character. It is even possible by bringing to bear counterirritants, to preclude these after-effects and mitigate the pain, as by rubbing or pinching the part." "In the case of a burn the conductivity of the tissues and vascular responses are even more evident, and such attempts to differentiate pain from sensation as a modality of feeling are futile. The fact that there may be analgesia without anæsthesia, and vice versa, is tentatively explained by the recent suggestion, that thermic and painful sensations find their way to the cortex through the gray matter of the cord instead of the fibrous columns, and affords us added data for the generalization for which we are now ready, viz: Feeling is always composed of two sets of factors, first, a sensational element, and second, a cognitive element. The sensations which directly participate in feeling are non-localized (general or total sensations), or are so acute as to irradiate, and thus ally themselves with total sensations. The cognitions are primarily such as identify the subjective state with the empirical ego. ${ }^{5}$

\begin{tabular}{l|l|l|l}
\hline I. Feelings. & Sensations. & $\begin{array}{l}\text { Sense gratification } \\
\text { and pain. }\end{array}$ & $\begin{array}{c}\text { General or Total } \\
\text { Feelings. }\end{array}$ \\
II. Occasions. & $\begin{array}{c}\text { Normal (moderate) } \\
\text { sensory stimuli. }\end{array}$ & $\begin{array}{c}\text { Super-normal stim- } \\
\text { uli, with tend- } \\
\text { ency to irradi- } \\
\text { ate. }\end{array}$ & $\begin{array}{c}\text { Diffuse (somatic), } \\
\text { especially "total" } \\
\text { stimuli. }\end{array}$ \\
\hline
\end{tabular}

"Bodily changes follow directly the perception of the exciting fact, and our feeling of the same changes as they occur is the emotion. Objects excite bodily changes by a pre-organized mechanism, and these changes are so indefinitely numerous and so subtle that the entire organism may be called a sounding-board, which every change of consciousness, however slight, may make reverberate. Every one of the bodily changes is felt acutely or obscurely the moment it occurs."

"Emotion consists (1) of general sensations of total, organic, or irradiating varieties which have in common a lack of localization and, as a result of associational laws, are amalgamated more or less closely with the empirical ego; (2) of more or less explicate or implicate cognitions (perceptions, intuitions) of the relation between the cause of the sensation and our well-being; (3) the emotion is more or less closely attached to various impulsive expressions which tend in various ways to intensify the two preceding. More in detail: The sensations are produced in

5 This, and most of what follows, is taken from "The Physiological and Psychological Basis of the Emotions," Wood's Reference Handbook of the Medical Sciences, vol. 9, 1893, Supplement, p. 270. 
most cases by vaso-motor' changes which, in turn, produce 'total sensations,' usually entirely unlocalized and not necessarily distinguished apart from the feeling. Such sensations may be recognized and to some extent analyzed, by practice. They precede the emotion proper and compose its sensational element. When one lies half asleep in the morning and a loud report startles him, the sudden surging of the blood to the periphery produces a familiar but indescribable sensation, which may include tingling at the finger tips, a curious twinge in the axils, a suffocating sensation in the chest, as more specific accompaniments. Then a flash of fancy depicts the burglar in the kitchen and a scene of bloodshed, danger to self, and the like; now perhaps a strange 'gone' feeling in the abdomen, and helpless atonic condition of muscles follow; then impulse dominates, and the tendency to spring to the defensive arises; all this before judgment announced that the cook has slammed the range door. Granting that the illustration has served to indicate the meaning of the statement above, it need require but brief experiment and selfobservation to show that vaso-motor and organic changes always accompany and afford a sensational basis for feelings. . . . . It is then no

\begin{tabular}{c|c|c|c}
\hline Emotions. & Impulses. & Sentiment. & Disposition. \\
$\begin{array}{c}\text { Somatic changes } \\
\text { occasionerl or ac- } \\
\text { companied by } \\
\text { cortical activity. }\end{array}$ & $\begin{array}{c}\text { Reflexes excited by } \\
\text { somatic and cor- } \\
\text { tical activity. }\end{array}$ & $\begin{array}{c}\text { Persistent cortical } \\
\text { changes. }\end{array}$ & $\begin{array}{c}\text { Reactions of corti- } \\
\text { cal residua or } \\
\text { new data of con- } \\
\text { sciousness. }\end{array}$ \\
\hline
\end{tabular}

mere figure which localizes the emotions in the heart or bowels, but a statement of sober physiological truth. A heartless man is one whose intellectual appreciation of the results of an act does not awaken sympathetic thrills in his physical being adequate to quicken in him a participatory or sympathetic state."

"The sensational elements in emotion are, first, pains and sense gratifications; second, obscure organic and total sensations which are not usually perceived as such, but are interpreted as part of the fecling; third, reproduced pains or gratifications always followed or accompanied by total sensations; fourth, representations which awaken by association either reproduced pains and gratifications which, in turn, give rise to total sensations, or the latter without the former; fifth, instincts which obey laws of association whose rational explanation lies in the development or phylogenetic history."

"Pain and sense gratification are more difficult to construe, because more direct and simple than the others named. So long as pain, etc., were regarded as simply exaggerated forms of orclinary sensation the problem was insoluble. That this is not the ease is suggested by the fact that they pursue other courses in the cord, and are associated more 
closely with thermic sensations. If a small area of the skin is isolated it is found that tickling with a feather is interpretated as warmth, and a thrust with a needle cannot be distinguished from heat. In other words, if the local signs by which position is recognized are excluded, the differences break down. It may be noted that general changes in temperatures states are closely connected with the general feelings, as witness a shudder or the cold chills of fear, and the glow of pleasure. Briefly stated, the peculiarity of pain and the intense gratification of sense which adapt them to become sources of feeling, is their diffusive (irradiative) character. If the current suggestion that algesic stimuli pass by conduction through the gray matter of the cord be substantiated, a much closer comection with the visceral centers than hitherto suggested may be postulated, and the thrill of pain can be readily interpreted as the sympathetic contraction wave passing throughout the vascular system. The evidence for the existence of adequate vaso-motor causes of the sensational element in emotion is largely subjective, but those familiar with nervous diseases will not lack for evidence that variations in circulation are powerful factors in emotional disturbances. . . . Flushes of cold and heat; tingling and palpations local and general; gusts and torrents in the blood; creeping, swelling, scintillation of the skin; giddiness and elation - these and indescribable 'all-over' sensations are easily separable from the intellectual appreciation, which may even be absent; and one may be a wondering spectator observing the irrational gyrations of his own sense to tintinnabulating stimuli upon which judgment turns the cold shoulder. Another class, afforded by the tickling and shuddering or irradiating sensations proper, further illustrate the necessity of diffusion in emotional sensation. The slight sensations of tickling, aided by subjective modifications, extend in most varied and irresistible sensations over the whole body. Its emotional character is almost wholly apart from the intellectual element. The shudder and chill which spring from a gritting sound or the velvety touch of a peach, imply in addition considerable instinctive elements."

The mechanism of the process of irradiation has been investigated by Professor Herrick (following Dogiel) in the case of certain vascular epithelia (especially in the sexual organs) whose excitation is connected with some of the most intense pleasurable experiences. ${ }^{7}$ Association tracts in the cortex illustrate the mechanism of irradiation in the case of the higher affective processes where the revival of residua plays an important part.

\footnotetext{
${ }^{6}$ Reference Handbook, pp. 270-272.

${ }^{7}$ See references in Baldwin's Dictionary of Philosophy and Psychology, article "Irradiation" and cf. Journal of Comparative Neurology, vol. 7, p. 155 (Mareh, 1898); vol. 2, 1892, pp. 111-114; vol. 5, 1895, pp. 1-32. For an illustration of the type of diffuse peripheral nerve plexus here referred to, see Herrick and Coghill, Journal of Comparaíive Neurology, vol. 7, p. 32-53 (July, 1898).
} 
The most localized forms of pleasure are accompanied by a peculiar nervous diffusion, as in tickling and the genial effect of warmth. This effect is known as irradiation and is also characteristic of higher states of pleasurable feeling. Both pain and pleasure depend on exalted stimuli, but the reaction of the system toward the stimuli largely determines their pleasurableness or painfulness. The same excitation may excite one or the other feeling at different times. ${ }^{8}$

This last statement contains an important thesis of the doctrine, namely, that summation or irradiation is painful or pleasurable only under certain conditions of intensity. As in the general statement of the equilibrium theory of consciousness of which this is a corollary, the condition of pain and pleasure is a state of relative tension or equilibrium. If pleasure meant merely ease of adjustment and pain difficulty of adjustment, then habit would carry with it the greatest pleasure and pain would be in direct ratio to the difficulty of adjustment, neither of which is uniformly the case. Up to the limit of normal functioning only, does pleasure increase with summation and subsequent irradiation. Beyond this point pain supervenes. It is only the relatively free discharge that is pleasurable. Supernormal irradiation is painful as well as supernormal summation. The limits vary from individual to individual. But the general principle holds that when the summation or resistance lies between certain limits of intensity determined by the structure and inheritance of the organism, the subsequent discharge or irradiation is pleasurable; if the summation is below or above these limits the discharge is painful. The apparent incompetence of the theory to explain "the pains of negative states, as ennui, etc., is only apparent. Whether a stimulus is painful or not depends not on the absolute intensity of the irritation, but on the capacity of the mechanism to transmit it. In ennui the sluggish system is incapable of reacting against the slight stimuli and their monotonous character causes a summation and intermittent discharge."

Sensation differs from feeling in the more definite localization of the stimulus, either by eccentric projection upon the periph-

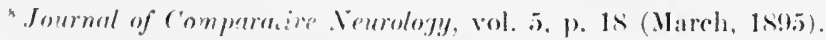

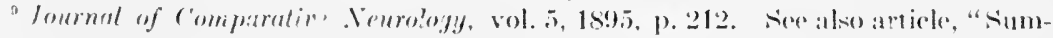
mation." in Ballwin's Dictionary of P'sychology and Philosophly.
} 
ery of the organism or by externalization of the object in the outside world.

"The finger resting on a rough surface affords a sensation of roughness referred to the object, but a feeling of disagreeableness or pain referred to the self. ${ }^{10}$

In common parlance no distinction is made. Experience is spoken of indiscriminately as sensation or feeling. And in fact they do not exist apart. But when this vague total sort of experience comes to be cognitively controlled, that is, when it comes to be more precisely localized and referred, we call it sensation rather than feeling. The sensation does not lose all affective tone but it is subordinated to the cognitive function.

"In general it may be said that the prominence of the feeling element is in inverse ratio to the perfection of the localization." "Those sense spheres in which localization is most pronounced are nearly or quite devoid of feeling." "There is much reason to think that the feeling element is a function of the extent of the lateral propagation of the stimulus in the centers while the sensation is the conscious product of the reaction upon the specific center. In the healthy body all normal stimuli as well as all responsive acts are calculated to produce pleasure, the amount of this enjoyment being dependent to a certain extent at least upon the range of irradiation or overflow of the excitement. Painful stimuli, on the other hand, are such as impose on the avenue of communication or organ of reception a larger burden than it can carry, whether because the excitement itself is too intense or by reason of some reduction in the power of the organ."

"The cognitive value of sensation, on the other hand, depends upon the series or system of brain centers called into play. No sensory impression passes directly from the organ of sense to the cortical center where it becomes conscious. Each sensation has an infra-cortical center where the materials from the sense organ are redistributed and combined with elements from the motor organs in the most complicated ways." "When a light falls on the eye and a definite change is produced in the pigment of the retina it must not be supposed that the resulting irritation of certain nervous end-organs is at once transmitted to the cortex to become the occasion of a sensation. On the contrary, the stimulus from the illuminated point passes to the coordinating apparatus in the quadrigemina where efferent currents arise and pass to the nuclei of the eye-muscle nerves and coördinating apparatus generally. After coördination the muscular effort involved in the coördinated act is registered; and this, with a variety of other acts below the level of consciousness, go together to the cortex and there affect the visual and other

${ }^{10}$ Journal of Comparative Neurology, vol. 4, December 1894, p. 226. 
centers so that the net result is not that of 'blueness,' let us say, but that of a particular degree of a particular kind of blueness in a definite place. Upon the equilibrium theory of consciousness it is not difficult to conceive that the tendency to coördinate and fuse various stimuli into one form of activity must be perpetually present, and as a matter of fact the most striking peculiarity of mental action is this same law of mental composition which finds its highest expression in what is called apperceptive action." 


\section{THE EQUILIBRIUM THEORY OF CONSCIOUSNESS}

Professor Herrick's theory of consciousness, which he frequently alluded to in his writings but which he nowhere systematically worked out, is bound up with his general view of the dynamic nature of the vital equilibrium and its relation to the special functions of the nervous system. The idea that the living organism is a moving balance of equilibrated forces is a familiar idea in recent theoretical biology, but this notion has not been extended in any thoroughgoing way to the phenomena of brain activity where structural and descriptive categories still hold almost exclusive sway.

"In no department of physical science is it so plain as in neurology that we are dealing wholly with dynamic elements. While it is true that in the structure of the brain we have to do with morphological details of marvelous complexity and the descriptive side of our work is concerned with the varying outlines, sizes, and combinations of cells, fibers, etc., and the still more recondite structures within the cells and their dendrites, yet it is always obvious that these morphological peculiarities are but the expressions of inner forces and their responses to others from without." "Correspondence in mode is the condition of identity implied by a dynamic theory, and the heterogeneity expressed in the forces of the body of a man may be expressed in the terms of the forces of a spermatozoön equally well. . . . . . Does not the body preserve its integrity in spite of the flux of its materials? Why should not the actual materials of the nucleoplasm be in a similar flux while retaining its form, i. e., its dynamic attributes?" "We venture to suggest that there is no such sharp distinction between nervous functioning and the intracellular processes of the ordinary non-nervous cell as our present terminology and usage suggest." There is in the case of many lower types of organism "a form of vital equilibrium so resident in the general system as to give rise to much the same phenomena of nervous unity as in the case of higher animals." "It, then, may be supposed that the circuit of nervous action in any part of the body passes through a variety of smaller somatic circuits and that the spheres of the two forms of activity overlap so that the return nerve current bears the influence of this interaction. The nervous equilibrium is only a central specialized part of a vital equilibrium embracing all the activities of the body."

11 "Physiological Corollaries of the Equilibrium Theory of Nervous Action and Control," Journal of Comparative Neurology, vol. 8, pp. 21-26 (July, 1898). Cf. also "The Vital Equilibrium and the Nervous System," Science, June 17, 1898, n. s., vol. 7, pp. 813-818. 


\section{In an article on "Psychological Corollaries of Modern Neurolo- gical Discoveries" $"$ "Professor Herrick said that}

"the condition of consciousness is not topographical but consists in the form of activity" (p. 155). "It is impossible to discover a specific portion or a definite kind of matter in which consciousness resides, for no complexity of the material unit could make intelligible the diversity in consciousness, while any complexity destroys the objective grounds of unity. It is equally hard to discover any physiological basis for the continuity of consciousness. The idea of consciousness as a property is accordingly abandoned and it remains to conceive of it as a form of energy. Pure energy with the attribute of spontaneity it could only be if it were in the mode of absolute equilibrium, in which its activities should be wholly reflected into themselves. This can only be predicated of infinite essence and it is necessary to substitute the conditions of relative equilibrium in a sphere of interfering activities. The last few year's have revealed in the cerebrum a mechanism of neural equilibration of unsuspected complexity, and all that we have recently learned of the physiology of the nerve stimulus only emphasizes the belief that the whole of the cortical complex is adapted to react as a unit, though not as an invariable unit. The great extent of the system of associational tracts and the facility with which new channels of overflow are set up or marked out is additional eridence in favor of an equilibrium theory of consciousness. The conditions of consciousness consist in the proper equilibrium of stimuli to produce a reflection of the stimuli upon the complex of which they form a part. The mechanism of this condition is found in the cortical centers, which are in continual action in such a way that a vortex of activity is in continual flux-each clement contributing to the balance of the whole. To this complex, external stimuli are continually being admitted, whether as separately unobserved elements from the general-sensation apparatus of the common sensorium (giving rise simply to the implicate concept of personal existence in space), or more specific stimuli through the avenues of the special sense organs. Every sense-content with its escort of reflexly-produced associated elements causes a more or less profound disturbance of the psychical equilibrium and the nature of this disturbance depends not alone on the intensity and state of concentration, but very largely on the kind of equilibrium already existing. . . . . The character of the conscious act (and the elements of consciousness are always acts), will of course depend upon the extent to which the several factors in the associational system participate in the equilibium. Each disturlance of the equilibrium spreads from the point of impact in such a way that progressively more of the possible reflex currents enter the complex, thus producing the extension from mere sensation to the higher processes of apperceptive association. A

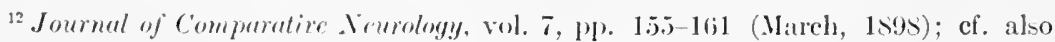
"The Material Vorsus the lonamic Psychology," Psyelological lieview, vol. ti, 1899, pp. $1>0-1>i$. 
conscious act is always a fluctuation of equilibrium, so that all cognitive elements are awakened in response to changes rather than invariable or monotonous stimuli" (pp. 155-157).

In the article on "Brain" in Baldwin's Dictionary of Philosophy and Psychology, Professor Herrick briefly states the theory as follows:

The theory of consciousness which seems best to conform to the conditions of brain structure and its observed unity is that each conscious state is an expression of the total equilibrium of the conscious mechanism, and that intercurrent stimuli are continually shifting the equilibrium from one to another class of activities. In other words, the sensation accompanying a given color presentation is not due to the vibrations in the visual center in the occipital lobe, but to the state of cortical equilibrium or the equation of cortical excitement when that color stimulus predominates. Previous vestigial excitements and coördinations with the data from other cortical centers all enter into the conscious presentation. As the wave of excitation passes from the visual center to other parts, the proportional participation of other centers increases, producing a composite containing more distantly related elements (p. 135).

The widely current belief in the anatomical separateness of the neurones entering into this neural equilibrium accords well with the theory and in fact either such an anatomical or some sort of a physiological barrier to the free discharge of nervous impulses is essential for the explanation of some of the facts. The theories of retraction of the neurone under varying functional conditions are particularly attractive in this connection, the education of the nervous system also being conceived as involving the development of new functional pathways as new associations are acquired and the short-circuiting of the old ones as activities become mechanized. Many of the peculiarities of inhibition or resistance to nerve stimuli may be explained as the result of contractions of the functional processes of the nerve cells.

[But much more fruitful in this connection are the more recent physiological theories of interneural resistance, particularly the carefully elaborated doctrine of the synapse of Sherrington.EDITOR.]

Whether or not the theory of retraction be accepted in its present form, it is important as an attempt to state a device for breaking and making the organic circuit necessary to conscious- 
ness, though this probably should be conceived as a functional rather than as an anatomical discontinuity. If a chemical or circulatory theory contains the true factor for determining these transfers of energy, as seems now more probable, the preceding conception will have to be revised to meet the demands of the facts. But that some sort of dynamic interchange takes place at this point is made probable by the structure of the nervous elements and by many converging lines of evidence, whether the nerve cells be conceived as anatomically separate or as forming a continuous network as some eminent investigators believe.

According to the dynamic theory

the act of consciousness is not the result of an excitation in any cell or cells, but is produced by the impinging of an æxthesodic ${ }^{13}$ upon a kinesodic system in reciprocal reaction. The transmission of nervous force does not produce a higher force; but the peculiar interference or increase of tension of nerve forces in antagonistic equilibrium does. Consciousness depends on the dynamic element-a translation of force into energy and thus, to us, there seems to be a complete hiatus between consciousness and all other phenomena. ${ }^{14}$

The motor reaction (in at least incipient form) is essential. The vast majority of our acts are performed without the aid of consciousness. But

even in cases where the subsidiary cortical current actually passes it may awaken no consciousness. This is explained upon a dynamic theory of consciousness. The cells are indeed excited by the current but, for whatever reason, no interference or kinesodic reaction is produced. Only when an antagonistic wave is set up is consciousness possible. This does not, however, prevent an unconscious process from awaking consciousness afterwards by vestigial action. . . . . Our judgment that part of our acts are unconscious means simply that the same sensory state is often combined with different amounts of kinesolic activities. ${ }^{17}$

The equilibrium theory of consciousness has to contend with a great obstacle in the form of a nearly universal popular fallacy. We have grown so accustomed to the necessity of localization of

\footnotetext{
${ }^{13}$ See Baldwin's Dirtionary of Philosophy and Psychology for definition of these terms.

"Journal of Comparalive Neurology, vol. 5, 1895, p. 21'2.

Is Journal of Compartive Neurology, wol. 5, 1s!95, p. $213-214$.
} 
all outer experiences that the mass of non-localizable experiences has acquired the force of a negative localization-a state of notoutsideness, so to say, a subjectivity. The grouping of the notoutside and the relatively constant as the empirical ego on its two sides of feeling and volition has received much study of late and it becomes apparent that the old theory of a simple central sense of effort is far too sophisticated a concept. So long as it persisted, it was natural that a search for the "seat of the soul" should be protracted even after the spatial element had been quite analytically treated by Kant and Lotze. We are driven by modern psychology to Lotze's position that a thing is where it acts and the being in the same place as another means that the two things have the power of interaction. It is plain that for a thing to be in a place apart from reacting upon the determinants of that place-in-which would be an impossible state to know of, if it existed, and an impossible thing to construe ontologically.

Given the proper form of activity, and consciousness is given. It will make no difference whether this form is a neural equilibrium in the entire nervous system or restricted to the cortex. The cortex alone of the nervous structures appears to afford evidence of the arrangement securing the equilibration demanded, and for this reason it may take rank as an organ of consciousness par excellence.

The brain is a prodigious mechanism for bringing diverse stimuli together in one continuum in the cortex. So far from a device for projecting stimuli upon one point, as imagined by Des Cartes and most speculative philosophers, the stimuli suffer a sort of dispersion in their path toward the field of consciousness. I discover that this mechanism is in a terrific state of activity. Currents of blood and lymph supplying highly complicated currents of energy are passing through the mechanism continually and doubtless the energy actually operating in the brain, if convertible into gross forms of work, would lift many tons literally miles high daily, for we deal here with what the physicist would call intramolecular types of forces as well as molecular and molar types of forces. Now all this vast activity reveals itself to us in scarcely any commensurate return. Just as the spectator looking at the solar system would see little evidence of the energy expressed in the equilibrated system of planets, every molecule of which is brimful of activity in balanced con- 
dition, so looking at the brain as a mechanism for mental work' we find it set on a hair-trigger, and a breath on an eyelash is adequate stimulus to liberate vast stores of readjusting energy.

All questions of the nature of sensation as well as of other mental activities hinge on the view taken as to the nature of consciousness. As consciousness is by its nature confessedly beyond the reach of analysis, we are forced by circumlocution to describe it in terms of its neurologieal concomitants. From many considerations, especially the structural coördinations and the unitary nature of consciousness, it seems most reasonable to conclude that the physiological basis of consciousness is the balance or counterpoise of the cortical stimuli.

From this point of view when the sensory stimulus is admitted to a cortical station there is at once a change of equilibrium-a setting of the neural excitement in the cells stimulated toward the rest of the cortical complex. This tide of nervous activity will obey laws of force, finding paths of least resistance, etc. The brain is so formed that it is possible for a great variation in the permeability to stimuli to exist at different times without any marked modification in the number or arrangement of the elements. It may be that the extent of the neurodendrites is the most important factor. It is known that the number and divisibility of these processes increases from youth to maturity. While they greatly increase the range of possible coördination (association), their presence may also serve to increase the total resistance and give rise to a sort of mental inertia. Most of the problems connected with sensation are connected with the content of sense and in reality belong to physiology and not psychology. Yet since the method used employs introspection in the study of this content, it may find a place in the psychological domain. The reason why one sense-content finds more ready entrance to the mechanism of consciousness in any given ease may be found in the intensity of the neurosis, in the frequency with which its path has been before used (habit) or the state of equilibrium at the time existing in the cortex. If the neural tide is already setting away from a point of disturbance in the auditory center it will be somewhat more difficult to foree a new wave from the visual center. The psychological study of sensation reduces to the study of the laws of association, and the great bulk of matter diseussed under sensation is found to belong with the study of sense-content. 
We must distinguish the content of sense from sensation. ${ }^{16}$ Here is the source of great confusion. Too often the content of sense is confused with sense perception. The content of sense at any given time is the sum of the affections of the lower or primary æsthesodic centers. In the visual field, for example, it is the totality of the immediate central reactions corresponding to the retinal excitations. We may think of them as distributed over homologous parts of the optic tectum; but it is probable that we should add the effects of certain optic reflexes set up with their æsthesodic reactions, and not improbable that it will be necessary to include modifications or accretions due to changes in the cortical visual area; but as yet there is no sensation, only a sense-content. Besides the contents of special senses-vision, audition, taste, smell-there is the whole æsthesodic contingent from the spinal cord, many of which never become sensations normally but may be brought into consciousness under exceptional conditions. Some perhaps are capable of entering sensation only as a quale of some other, having no localizable tag suiting them to independent recognition or isolation. These, however, are just as real a part of the content of sense as the pre-sensational elements of color or pain.

Now it is evident to ordinary experience that in many cases the act of sensing a sense-content is really an act, not an occurrence. We fix that particular element. It is immaterial how we are impelled to the fixation. It is an expression of our spontaneity, a reaction of the subject. Many considerations justify us in supposing that an act of consciousness is a reaction of consciousness. There are, it is true, in the sense-content of vision focal and marginal impressions, but the physical mechanism is well known. There is something similar in the auditory field whose physical mechanism is obscure. There is nothing of the sort in the other senses except skin-sensation and there the physical origin is beautifully illustrated by the localization experiments. The localization apparatus of the senses has apparently suggested the theory of focal and marginal consciousness. We believe that a proper interpretation of experience removes the ground for this assumption. The various intensities of sense-impressions con-

1" Cf. "Focal and Marginal Consciousness," Psychological Review, vol. 3, 1896, pp. $193-195$. 
stitute the basis for focal and marginal sense-contents. In like manner there is a perspective of vestiges presented to consciousness.

We may consider what the effect is when one or another content of sense is admitted to the "synsorium." If it is a single color (let us say) then the balance is disturbed in a given characteristic way at the moment of admittance. We perceive a color. If instead there is a retinal picture of a landscape, the equilibrium is disturbed in a different way, and one which produces its instaneous impression; but this is followed by the after-shower of innumerable vestigial impressions from the optic and other associated areas which each in turn affect the equilibrium of the synsorium. We insist that there must be in this ultimate mechanism of consciousness an absolute succession. A wave of consciousness with focal and marginal parts is inconsistent with any conceivable means of bringing sense-impressions to the æsthesodic and kinesodic systems of the cortex. Only so can intimate connection of various forms of innervation with perception be explained. The discussion of this point is difficult, and need not be attempted. Probably most psychologists will agree that consciousness is an act, not a state; and that it is a pivotal act which takes place in the very focus of our being. The unity of consciousness may be interpreted to mean that consciousness is only possible when the rsthesodic and kinesodic currents affect the equilibrium of the entire mechanism of consciousness. It seems possible to conceive of the situation as an instance of most complicated equilibrium where each element of the conscious mechanism (the synsorium) contributes its tension to the balance of the whole. However this tension is effected, a conscious state follows.

Of course we encounter a difficulty at this point. Has the soul any separate existence or is energy conceived simply as a sort of spring-board against which matter or force impinges? We answer that the transformation of forces produces real changes in the eareer of energy. Is it possible for energy in one form to react on energy in another directly? If we say "yes," it is natural to object that this reaction would produce resistance and so force. If we say "no," what becomes of a career of energy or the life of the soul. We must believe that there is no direct reaction of energy on energy - of soul on soul; but that the form 
in which energy occurs will determine the nature of the reaction as force. If we admit that the energy of a conscious being is only a sort of via inter quam, we must insist that it is no homogeneous medium. In the mind the forms of reaction are complex and the forms of intermediary energy are also complex. The equilibrated forces of the organ produce a stream of highly differential energy by which new reactions are profoundly modified. Every translation of force is attended with production of energy, but the kind or phase of energy differs in accordance with the nature of the force. The complete synthesis of diverse forces of a special grade into homogeneous energy in a vital organism produces consciousness. There may be something corresponding in the case of every production of energy, but we cannot know it; for consciousness reveals itself only in self-consciousness. Self-consciousness is the result of reflected energy becoming reconverted into force. Will is the energy evolved in the higher sphere indicated.

Here is a difficult point. Transition from force to energy under suitable conditions is conscious and the energy so set free is will. Will is of a sort with all energy; it is spontaneous activity and only conditioned by its own form. It becomes our will only in self-conscious states. Consciousness is not a force but a quale of the will.

This was brought out somewhat more concretely by Professor Herrick in 1893 in the course of a critique of Münsterberg's "Die Willenshandlung," where he says: ${ }^{17}$

Perhaps we have here precisely the difference between will and impulse that the former is ' reinforced by the totality of our personality.' It is certainly not the province of physiological psychology to enquire more closely into the nature of the ego, but it appears that this science may have incidentally and perhaps unintentionally done very good service to rational psychology by showing that there is no amphibious bugaboo between the conscious element and the voluntary motion. There is no mongrel will with head of Jove but whose tail executes fishlike and simply physical wriggles. For this much, thanks, and thanks too for the assurance that the will is born of the intelligent elements in our being and clothed with feelings. It is no isolated "faculty"-no poor third of a divided personality, but it is the whole ego in its direct expression, an

${ }^{17}$ "The Scope and Methods of Comparative Psychology," Denison Quarterly, vol. 1, Nos. 1 to $4,1903$. 
expression which varies in richness and significance as the horizon of our experience widens (p. 279).

Looking again at the simple facts of sensori-motor response, it appears that we have neglected a most important point in the process when we say that the force is all returned, viz: that its form has changed and the nature of the change depends on the nature of the subject. We know that our responses to outward stimuli depend on the temporary as well as the permanent disposition of the organism. When a reflex circuit is opened, the response depends on the anatomical structure of the spinal cord. When an automatic circuit is opened, responses follow depending on complicated reactions of 1 art on par. When conscious circuits are opened, the responses depend on whatever produces consciousness. Of course it will be replied that the structure of the organism is the product of previous stimuli, but that only carries us back a step or two. How organization is possible is just the problem. Organization is the formation of complicated states of equilibrium and all such states of equilibrium result in evolution of energy capable of changing the mode of force (as in our illustration of impinging bodies). These enormously complicated rortices of energy constitute the soul of the organism.

We have seen that activity is the sole element of experience, and its varying forms are, in a sense, the algebraic expressions for interactions. Consciousness is one of the coördinate expressions of the totality of activities of certain grades. The only condition of force in which no force is lost and yet a new mode is introduced, is equilibrium. It is natural to apply the same suggestion here. Flint met steel and a simple kind of force was translated into higher and back again. There was a flash. Trace the forces and weigh them; they are all there, but the fact of change is a fact of a higher kind not weighed in your balance. Applying the same reasoning to the mental phenomena, we see that the forces whose intermittent stream feeds the psychical lose nothing in their passage through the mind; the stream is undiminished, but there has been a transformation the peculiar form of which has been the essential psychical content. The mind may be compared to a registration apparatus which registers by strokes on a dial the passage of a certain quantity of fluid flowing through its chamber. Consciousness is a manifestation 
due to a form of equilibrated energies, which particular type of energic equilibrium may only be reached after the amount of energy reaches a certain quantum. Only those forms of energy have consciousness which are adapted to converge and be reflected in harmonious modes.

Could we imagine a perfect mirror which reflected every surrounding object but was itself invisible, we might find it difficult to make out the qualities of the mirror, even though we became very familiar with the laws of reflection. The soul is such a mirror, and all the images which it produces are, so far as we can tell, reflections of physical phenomena. 


\section{BODY AND SOUL}

The term "mental state" is as ambiguous and contradictory as the more comprehensive designation "mental faculty;" indeed, the latter is less open to criticism than the former. What we really have to do with is an activity or its absence. In the latter case there is a "state" of non-existence or of not-being. In the former case we have an unwarranted postulate. A state of activity implies a something apart from the activity which may at some other time be in a state of inactivity. But this assumption is gratuitous. Mind is not a something which can under suitable conditions get into "a state," and so produce this and that activity recognized as mental. The totality of the activities constitutes the mind.

But is there not a physical basis of mind of which these activities may be said to be states? What the physical basis of mind is it does not here concern us to inquire. Whatever this is, mind is not a state of matter. If one chooses to describe mind as one of the forms of the activities of matter, we shall have no quarrel with him if the same treatment be applied to the other so-called qualities of matter. When this is done, we have a collection of activities and nothing else. Common usage describes matter at one moment as something whose reality consists in its ability to be affected in certain ways by forces. What this property is which permits force to affect it we are not told. But plainly it is itself a disguised force, for it is able to alter the mode of force. At other times usage seems to assume that the properties of matter are forces. Without this assumption, it is impossible to treat of the phenomena of elasticity. It is evident that this whole field is clothed in densest obscurity and crudest ambiguity. It is necessary to accept one or the other basis of physical reality: (1) matter as a metaphysical generator of force, (2) force as a multiform expression of a spontaneous primal energy back of which it is impossible and unnecessary to go.

Everyday experience teaches us that there is a certain segment of our objective experience that has a closer relation to the ego than other portions. The child may offer to its toe a 
portion of the cake it is eating with no recognition of a difference between this object and other living objects like the kitten with which it is playing; but it is difficult for the adult to avoid thinking of the body as an integral portion of self. The child also may weep because of a fancied injury to an inanimate object with an altruism of which the adult is incapable, and, on the other hand, we might imagine a state of being in which an injury to another or an ideal or ethical wrong would excite quite as deep response as a wound to the body. We know of the existence of the body as a mass of "matter" in the same way as we learn of the existence of other material bodies by the testimony of our externalizing senses; but in addition to this source of information we have the associated information from the partially or completely unlocalized feelings of pain and effort, etc. A blow on the toe is not only seen to take place, but the feeling of pain resulting is added; while even the tactile sense is so modified that it reports the sensation as subjective, $i$. e., localized within the body rather than outside of it. We discover that this body is composed of a vast number of coördinated parts and do not fail to note that while the liver, for example, may be seen and felt, as any other portion of matter may be, yet in its state of coördinated or structural differentiation it has other functionsit secretes bile and stores glycogen, etc. Just as the tactile property is due to a peculiar arrangement of molecules whose essential nature consists in the putting forth of certain forms of activity giving rise to the resistance we feel, so the organization into the so-called structure of the organ is simply a revelation in a roundabout way of the fact that the coördination is carried further in progressively involved cycles till the result is the more obscure function of secretion. One of the processes is just as much a result of the structure as the other (and no more). It is a common practice to contrast the body, which is present to the senses, with the soul which is felt as the immediate product of consciousness. It is true that the soul is not independent of the body in our experience, but is distinctly associated with it and manifests itself in direct and indissoluble association with a special organ-the central nervous system. Materialistic psychologists have not hesitated to state that the relation between the brain and the production of thought is as direct as that between the liver and the production of bile. This is a some- 
what revolting statement, but the method of escape from it is by the recognition of the measure of truth in it. It is possible that bile might be secreted without a liver and entirely probable that thought can exist without a brain; but in the case of man, the organ we call a brain is the evidence appealing to the senses of the existence of those marvelously complicated acts which make up the soul-life in man. When we view an object in a glass, at the same time looking at the object itself, we need not be surprised that the movements of the image are synchronous with those of the object nor invent theories to account for the explanation of the conformity observed. Still less do we seek to show that movements of the image in the glass cause those of the object itself. And yet the common attempt to indicate how the brain produces thought is not more absurd than the suppositions mentioned.

The theories respecting the relation between the soul and body are, of course, much influenced by the view entertained as to the intrinsic nature of the two subjects of thought. For those who regard body and soul as distinct and disparate entities, a difficulty at once arises in accounting for the constant connection between the brain and thought. We are told that the nervous processes produce the phenomena of consciousness which we call sensation, feeling, perception, impulse and will. Still we are assured that these "psychical activities" are the expression of the life of a peculiar being which is immaterial and consequently not in space and is a metaphysical unit and so indivisible that it must be in only one place at a time, and other interesting things all equally undemonstrable and unintelligible. In some way the material body acts upon the immaterial soul to cause the latter to act as it does in the processes of thought and volition and feeling. All physical analogies here seem to break down. If we attempt to employ the analogy of the transfer of a physical force from one mass of matter to another we have the difficulty confronting us that it is insisted that the soul is as unlike as possible to the matter of the body from which the force is supposed to emanate. But by all analogy likeness is a necessary condition for the transfer of force from one body to another and it is thought by some logicians that the predicate of likeness is really only the statement in another way of the fact that the two objects compared are capable of reacting on each other. Again in the view held by the advaneed school of physicists, the passage of a force 
from one body to another is really a transference of the properties of the one to the other, for the properties are simply the forces, resident in the individual.

Still farther difficulties rise as one proceeds, one of the most serious of which grows out of the attempt to reconcile the attribute of freedom, i. e., the spontaneity of the soul's action, with the observation that the form of the soul's activities seems to be conditioned by the external stimuli which affect the nervous system. Our text books are filled with endless and usually profitless discussions intended to prove or disprove the freedom of the soul to act in any way it choses in view of given inducements. The belief that the freedom of the will requires that it should be possible for the soul to act at any time in a way determined neither by the circumstances of the environment or by the inner nature of the soul itself or by any combination or interaction of these two elements is entertained only by those who fail to see its grotesque absurdity; but the influence of some form of this dogma is felt where it would not be explicitly defended.

The analogy of the conservation of energy also gives trouble, for it is plain that if the forces which act on the nervous system from without are transformed till they at last produce in the soul the sensations, etc., to which a psychical nature is attributed, then it seems superfluous to require a separate and superphysical cause for the same act. On the other hand, if the external stimulus really has no efficiency in the production of the act of consciousness, why should the stimulus seem to be a necessary prerequisite? Force is lost in either view and this is contrary to the dogma of physics. Sometimes the conscious process is called an epiphenomenon, $i$. e., a phenomenon or appearance not the result of the action but a shadow-like accompaniment of the activity. The difficulty also arises that we unconsciously undermine the freedom of the will in denying the element of real energy in the psychical phenomena because it is a matter of every day experience that our psychical experiences apparently issue in voluntary acts, each of which has its material effect. The theory of the reciprocal action between the soul and body, in the crude form in which it usually appears, may accordingly be set aside for the present while we consider the claims of the theory of identity of these two elements.

The claim is made that there is no real distinction between the 
physical and psychical. Two forms of this theory are possible, the one assumes that matter is the only real thing and that the so-called spiritual phenomena are only properties of matter. Materialism finds no evidence of a second reality aside from the matter of a body. Its spirit can at most be but an abstraction or a special way of considering the properties of matter itself, which is fully competent to explain all the peculiarities of the conscious life. On the other hand, spiritualism replies that all that we know consists of sensations and other forms of psychical manifestation and that matter is only an unjustifiable inference. The properties of matter, such as extension and inertia, are names for the constant form of our experiences. The second form of the identity theory is more likely to appeal to the thoughtful student than the first, yet it is in several respects unsatisfying to the critical mind.

The commonest way of attempting a reconciliation of the difficulties above noted at the present time is by the supposition that the same process may have two aspects. Fechner compared the nervous and the psychical to the outer and the inner aspects of a curve. Seen from without it is convex; seen from within, it is concave. A concave line is different from a convex one, but yet they seem to be one and the same line viewed from different points of view. This is a clever illustration, but it must not be forgotten that it is only an illustration and is not an explanation. Outside and inside of a curve are mathematical ideas implying, among other things, certain points of reference or loci without which such a distinction as that between the outside and the inside of a curve is impossible. To press the illustration is to to be guilty of a subtle form of begging the question, for it is this difference between the inside and the outside point of view that is sought to be defined.

Let us see if we may not adjust the difficulties of this problem in a way that, while it shall not assume to offer a solution of a problem in its nature to us insoluble, yet shall leave us in a state of greater satisfaction with the practical relation of man to the two forms in which his experience appeals to him. First, then, the only absolute criterion of being we know is change or activity. A non-acting thing is nothing. Even an imaginary thing is an active thing. In our own experience of our purest acts we are unconscious of anything back of the act producing the act. We seem to will spontaneously. Pure activity without the ele- 
ment of interference or resistance we may call pure energy. Such a form of activity is rarely, if ever, met with in human experience. All activities studied in physical science are found subject to resistance and are called forces. All such forces are convertible and it is a natural inference that they maybe reduced to a common form. Such a primitive or fundamental form would be pure, $i$. e., there would be no mixture, there would therefore be no interference or resistance and such a condition of force would be the theoretical pure energy (Pure Being of the philosophers). Materiality is an expression of the forces in more or less permanent equilibrium in the individuals of experience as entering our senses. The degree of complexity of such equilibrium is various and this variety expresses itself in a series of successively "higher" properties. In living matter the coördination is very extensive and complicated, and the equilibrium very perfect and tends to be self-perpetuating. The various degrees or grades of consciousness are expressions of successively higher forms of the coördination. Such expressions in our experience are found linked with the vital equilibrium of individuals, and the cycle of psychical evolution is connected with and bound up in the cycle of vital evolution, yet there is nothing to prove that the psychical need be restricted to the association with the individual with which it is now associated. It is conceivable that the psychical differentiation should acquire connections with other forms of body.

To sum up this discussion: It is not true that the soul and the body are disparate and wholly incapable of reconcilation, for they are different expressions of force associated as parts of one system. It is not true that the two are identical, for they differ in form and this difference is of a nature to distinguish the physical from the psychical toto ccelo. It is not true that the one is the outside and the other the inside of the same curve; they are not different aspects of identity, but they are parts of a single system and so intimately related, but being different in form they are in that fact different in essence. It is to be expected that the ideas presented may seem obscure because of their unfamiliarity, but the thought is after all the simplest form of an expression of the results of unsophisticated experience. ${ }^{18}$

\footnotetext{
${ }^{18}$ On this general subject ef. also "Recent Contributions to the Body-Mind Controversy," Journal of Comparative Neurology and Psychology, vol. 14, no. 5 (September, 1904); and "Mind and Body-The Dynamic View," Psychological Review, vol. 11, 1904, pp. 395-409.
} 


\section{THE CONCEPT OF INDIVIDUALITY}

The greatest difficulty the dynamic philosophy encounters is that involved in accounting for individuality. If all energy is bound together in one universe, all being parts of the whole and the whole felt or implicate in every part, how does the part become discrete? The reply is simply that creation is the introduction of mode (diversity, heterogeneity), and so far as our universe is concerned this diversity is primary. Given rhythmical variation and it can be conceived (from physical analogies which we may accept as valid) that two centers of activity may impinge upon one another in an infinity of ways whose one limit is identity and whose other limit is opposition. The results of such interference will conceivably vary also through an infinity and these resultants will be modes of activity differing from either of the primary energic modes.

When a certain number of energic centers or factors are brought, after successive trials and selections, into certain mutually harmonious phases, these may become bound into a syntheticum or inferior organism which realizes our concept of individual. Let us suppose, for example, a more or less uniform stroma or energic field within which are playing a variety of forms of energy. This, let us say, is the plastic magma of a granite. Now certain of these forces become correlated by virtue of coherencies in mode and there arises a crystal of feldspar, i.e., a certain definite aggregate of activities expressing themselves as properties to our senses via our scientific apparatus. The energy has become less facile, and has become compounded into a more permanent form. There were reasons for the tendency for this particular appearance in the total formula of the energy in the magma, and not one but many crystals were formed; there was a sort of feldspathic epidemic. Now the newly formed units or freshly crystallized individuals exert their reactionary energy on the magma and tend to absorb all of the appropriate forms of energy to themselves. The crystals grow. It the same time they negatively tend to polarize the residual energy in the magma and new units of synthesized energy appear. The new syntheticum may be horn- 
blende. What remains develops certain harmonies, and quartz envelops the preformed elements filling the interspaces. The "molecular" energies of each of these ingredients combine to form most resistant and permanent elements. Of course there is constant reaction. There is tension between the elements; there is chemical, thermal, electrical interaction, and many others of which we know nothing, and it is impossible to deny that the quartz is in constant energic communication with elements in Sirius. This "social" relation is no bar to a high degree of individualization.

In the crystal there is the power of assimilation and reproduction. New little crystals of perfect form are formed as parts or adherents of larger ones. There is no particular reason for denying that this tendency, however weak and limited to special conditions, is analogous to the reproductive tendency of animate beings. A species of mineral, it is insisted, differs from a species of animal in that the individuals forming a species of mineral arise freely, independently of any previous individual. Thus our quartz grains arise in the magma independently of any other quartz grains, while an individual of a species of animal cannot arise independently of some pre-existing animal of the same species. To this it may be replied that it is yet unproven that spontaneous generation must not be called in to account for the origin of life (if not, there is a break in evolution) and also that the allimportant thing in both cases is that there shall be a certain assemblage of properly adjusted energic forms in coadaptation:in the undifferentiated magma of the granite on one hand and in the germinal elements or buds of the animate species on the other. Inasmuch as it is demonstrable that the presence of a crystal is a determinant to the formation of others in the magma, it is only necessary to suppose that in the more complex composition of animate individuals this (at first adventitious) aid becomes finally a prerequisite. Thus the difference between the origin of new individuals in the two kingdoms reduces to a minimum.

Now, as we saw, the possibility of variation in the manner of impingement, where two forces interact, varies between identity and opposition. But it is in accordance with physical analogy that, to our senses at least, there should be "critical angles" or "genetic modes." In passing from identity to opposition, those stages of 
interaction up to a certain point call out a sort of response in our senses having a likeness imposed by the fact (let us say) that they appeal to one organ. Another segment may find no access to our sensorium, and so on.

Now if these extrinsic reactions are capable of awakening various kinds of consciousness in the observer, may it not well be that the intrinsic element in each coördinated energic system may have a similar power and that it should have a like analytic form so that there should be varying forms of genetic modes corresponding to the several segments of intrinsic reaction as well as in the case of extrinsic reactions? But it must be observed that the extrinsic reactions imply intrinsic for their realization. In fact it seems that only in the form of intrinsic reactions within an equilibrated unit of energy can these genetic modes be formed. Among such, consciousness may rank-not simply human consciousness, but whatever may be possible in the way of intrinsic reaction in thing-in-itself.

The resistance which Professor Herrick postulates as equally fundamental with spontaneous energy, is the parent of individuality. ${ }^{19}$ Individuality consists of a particular form of expression of the spontaneity through the interfering resistance constituting the record of individual evolution. The individual is a segment only of a larger arc, the illumined portion of an endless trajectory. The basis of unity is found in the vector character of reactions. The cyclical processes constituting the individual life are not inconsistent with the idea that the individual existence is a condition of equilibrium. Just as a gyrating storm may move over a given path, its trajectory obeying the general laws of cyclones, while the inner motions of the vortex are unaltered or attain an independent maximum and minimum; so the lifehistory has its own laws, while the inner life preserves its integrity.

On the open plains in the western desert a slender column of dust rising perhaps 150 feet in the apparently still air may be scen slowly moving at the rate at which a man might walk, sometimes pursuing a uniform path, at others suddenly turning. Sometimes this spectre hastens as though urged by a sudden impulse; again it loiters as though unable to make up its mind.

"Ci. "The Dynamic Concept of the Individual," Journel of Philesophy. Psycheolongy and scientifie .Metherds, vol. 1. p. 374, 1901. 
The appearance may endure for hours and may be traced for scores of miles over the trackless plain. The sand in it (that is the material) is continually changing as is the component air. The little vortex is the result of the union of equilibrated forces, and is just as much a real object as is a tree or a man. It is an individual, but its unity obviously consists in the perpetuation of a definite form of coördinated activity. The currents of air which compose it are eventually merged in the general system of atmospheric currents, and the individuality is lost. It is possible to imagine a set of intricately coördinated currents of force so adjusted as to give rise to a property which we call feeling or consciousness. The human organism is especially adapted to produce the background of constant experience across which is flung the flickering image of the passing events. ${ }^{20}$

In a uniform medium, as has abundantly been shown, the only condition of individuality is that of vector activity. Vortex rings serve as illustrations. The discussion of vortex atoms has brought out this peculiarity. Two forms of activity appeal to our senses; first, progressive or translational or molar; second, selfcentered or vector activities. In the first case the point is conceived as moving in a right line or some other progressive manner so that the motion is indeterminate; in the second case the motion is cyclical and the center of reference is stable. In ordinary parlance, when a body falls, the motion is of the first sort, but when brought to rest the motion is transformed into the second state. The body is in a state of rest and with reference to adjacent bodies is in equilibrium.

Vector motions have a remarkable stabilizing power, as witness, for example, the gyroscope. The two classes of motion have been called molar and molecular respectively, but this perhaps involves too large a hypothetical step. The crude illustrations used may serve to show at least that the same force may have a conservative power in one phase and a dispersive power in another. But let one take the still simpler illustration of a solenoid. A current of electricity passing through a straight wire produces, it is true, an induction-effect on the neighboring metals; but, when the same current is forced to pass through a spiral path, the complex acquires

\footnotetext{
${ }^{20}$ Some of the pages which follow have appeared under the title "The Nature of the Soul and the Possibility of a Psycho-mechanic," in the Psychological Review, rol. 14 , no. 3 , Мay, 1907.
} 
an individuality -it is polarized as a whole and acts as a magnet. Similar solenoids react against it, and a system could be formed from innumerable solenoids in equilibrium which would vary with the currents sent through the several elements, while the entire system would be in equilibrium at all times. While it is not suggested that the brain cells are solenoids or anything of so crude a nature as that, yet it is believed that the afferent currents passing into the cortex produce in more or fewer of the brain cells a system of intrinsic activities which react, each with each, in a total cortical equilibrium which for each instant is the dynamic aspect of a state of consciousness - an act of mind. The whole involved activity, now more now less, at any given moment, is equilibrated and forms a self-centered process of unitary nature. The structural mechanism of the brain is an uninterrupted flux of activity of a vital character. Vital activities are all analogous, rotational or vector, we might say (for illustration solely) as contrasted to translational or indeterminate or progressive activities. To be more general, what we call structure is evidence of statically condensed energy (energy in vector states) and this is competent to enter into reaction with afferent impulses and convert them into vector activities. The sum of the equilibrated activities in the body form its vital continuum. One phase of the equilibrated continuum is the activitity of consciousness. So far as we know, the conscious continuum is associated with the total vital complex. It is not proven that any other form of equilibrated vector forces is capable of assimilating the afferent stimuli and converting them into similar terms and so converting them into a conscious activity, though it may be said that we know of nothing to the contrary. ${ }^{21}$

One moves a lever upon a friction-clutch, and tooth engages wheel and band moves upon pulley, till the whir of a thousand wheels follows. Could we think of the friction-pulley as gradually creating the machinery of the mill out of existing energy in resisting phases, we would have a rough image of the vital organism.

But do you mean that my foot is part of my soul? Yes, I mean that the vital activities in my foot form part of my vital

\footnotetext{
21 (f. "Nind and Body-The Dynamic View," Psychological Review, vol. 11, expece. pl. 406 iog (November 1, 1904.)
} 
equilibrium and, in so far as these contain conscious participants in the stream of consciousness, they form part of the soul. But, if I amputate a foot, do I mutilate a soul? Certainly, though it may be better to enter into life maimed than to retain a foot and go elsewhere. By cutting off a finger a child's soul may be maimed of musical faculty. There are organs, the amputation of which affects the entire character for life, and one does not willingly dispense with the frontal lobes of the brain even if he does not know precisely what purpose they serve.

On the other hand, it is possible to add to the sphere of the vital activities, as when I place spectacles upon my nose or apply my hand to the throttle of a locomotive. Where, then, is the limit of self? It is not for me to draw it. I will not cut the narrow isthmus of flesh which connects me with my twin-the universe. The ancients believed that the eye shot out rays to grasp the objects of the visual world. What tentacula has not modern science produced extending from all our organs to the phenomenal world?

But if we may not define the outer limits of the individual life, do we not destroy individuality? Only seemingly, for we need not despair of locating its center because the periphery of its sphere of activity is indeterminate. The leaven of life may be small; but, given time and appropriate conditions, it will leaven the whole lump.

Our analogy of the vector motions carried out would lead to the conclusion that, wherever such a center originated, it would tend to assimilate to itself all such activities as are capable of offering resistance to it and would, by virtue of the form or mode of its activity, cause allied activities to accumulate in harmonious adjustment about it, enlarging, and, at the same time, intensifying the energy in the original equilibrium.

Disturbances of this equilibrium there will be, but it will be one of the hardest things to exterminate we can imagine, for it is entrenched in one of the most recondite energic conditions of the universe. Seed may be dried for years in the tombs but it will still germinate. No persecution ever succeeds in stamping out a vital truth. It is not to be wondered at that humanity has enduring faith in a life eternal, but this is not the life of the soul, if by the soul we mean the "stream of consciousness." In so far as our life as a whole fits into the complicated sphere of 
the universal life it will be imperishable. Maimed and crippled it may be, we crawl over the threshold of one world into the fresh glory of another, but if the life be really there, it will have no difficulty in assimilating to itself a body fit for its use, as the acorn finds its own body in the crevices of the rock and builds it forth in strict accordance with the pattern set on the peculiarities of its own vital equilibrium.

We need not look for pangens, biophores, gemmules, micellæ, and the like, in our study of heredity, or if we find them, we shall regard them as visible manifestations in some temporary form of types of equilibrated energy, vortices of specialized activity, specific in its form. The newt will grow a new leg. It is possible that the leg might grow a new newt if we were able to keep the conditions favorable, just as a branch may grow a new tree. There is nothing so violently incongruous as might appear in the childish planting of nail parings in the hope of raising a crop of men. ${ }^{22}$

The most essential element of consciousness is its focal character. This is precisely an individualizing moment. Our point of reference about which we construct the locus formula of our life may be continually .changing, but it is precisely the "I" of consciousness and cannot be diffuse or extended. It is the intrinsic, self-reflected, epicyclic character of consciousness that creates individuals. It is the one and only individualizing moment. The self-point of consciousness is in essence unchangeable in so far as it is a point of ultimate reference, the standard of all realizing. Doubtless our activities might form part in a greater or social whole which might have its consciousness of a higher order (its more intricate equilibrium); but I do not see that it would follow that our consciousness would be involved in it or that the higher consciousness would be felt in ours. It would only be in so far as our activities entered into reaction with all, that we should approximate to a consciousness of the

\footnotetext{
"2. W. W. E. Ritter, American Naturalist, November, 1903, in which it is stated that Miss Sarah P. Monks has succeeded with the Starfish (Platria or Linckia fascialis) in regenerating the body from simple rays. Cf. Haeckel, Zcitschr. wiss. Zool Bd. 30, 1878. Cf. Herrick, Journal Comparative Neurology, vol. 8, no. 1, 1898, pp 26-27. (Cf. also the posthumous article by Professor Herrick, "Applieation of Dynamic Theory to l'hysiological Problems," Journal Comparative Neurology and Psychology, vol. 16, no. 5,1906 .)
} 
"All;" but this would still be egocentric. There is perhaps some satisfaction in gathering those facts of our experience which appeal to our senses under one head-." the universe" - and the postulates of our reason under another and calling it "God," but the dualism is in our method, not in the subject-matter.

Of course it is soon discovered that many individuals are wrapped up in any one so-called individual and that units of a higher order (species, etc.) may be formed. But any given individual object, e. $g$., any given man, has his own individual formula descriptive of the totality of the reactions (or shall we say the trajectory or career). ${ }^{23}$ Here is a species of social ants. That species refuses to exist if it does not express itself in drones, warriors, queens, nurses, etc.; in short the individual is not the unit but the society or colony. This interdependence is such that the "species" cannot manifest itself except in these social terms. So with man. The social reaction has become necessary to the individual development. Life cannot continue without lateral reaction; most forms are diœcious and sexual relation is essential even to racial persistence of type. In like manner a tremendous range of coördinated (lateral) forces are fused in the individual consciousness. This transverse or social relation, then, is real. Our concept of a species finds its logical and metaphysical justification in the postulate of a unitary organism (cosmos), just as all other metaphysical verities must.

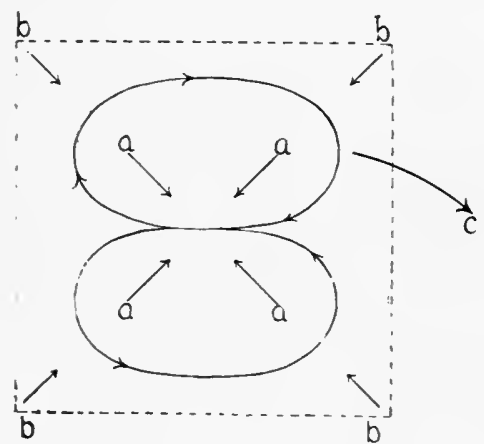

FIg. 1 .

Consciousness is the individualizing moment, the intrinsic aspect of the career but not that career. Given a concentric, egocentric, or individualized motor complex capable of acting and reacting upon all other suitable complexes, one may discriminate between the inner equilibrium-stress and the reaction-phase of this energic unit. Thus the accompanying diagram, fig. 1 , illustrates the locus of a certain vector force projected on a plane geometrically; $a-a$ are egocentric (centripetal) forces in equilibrium 
This is subject to variation as external forces, $b-b$, impinge on it and resultant activities $(c)$ constitute a trajectory of the system as a whole. Now, $a-a=$ consciousness, $c=$ effect on external observer. In just so far as the locus formula of my neighbor is like mine and his external (environmental) elements are the same as mine will his consciousness be like mine. It can never be identical. The very fact that he is in another place means that his experience is $\left(b-b^{n}\right)_{x}$ not $\left(b-b^{n}\right)$ as mine is. His $(c)$ will be $(c) y$ but $y$ may be almost negligible. Now if my locus formula grows so complex as to receive the whole series of $\left(b-b^{\prime}-b^{\infty}\right), \mathrm{my}$ consciousness will from time to time, or when complete, exhaust all $\left(a-a^{\infty}\right)$, and your consciousness will be sensibly equal to mine, if likewise extended. Such harmony will result as will make sympathy complete. There will be a case when $(c)$ is sensibly parallel to $\left(c^{\prime}\right)$. There will be no conflict in our lives. This will not make your consciousness mine unless our individuality be merged. There is no such thing as summing up the consciousness or experience of two individuals. Your career is to me a part of $\left(b-b^{n}\right)$. It may be in antagonistic or in concurrent mode. When nodes of your career rhythmically correspond with my rhythm, reinforcement occurs. This produces a change in my consciousness. Music produces a delightful modification of my consciousness-perhaps also of yours-but the appreciation you have does not affect mine directly.

On the above view there can be no such thing as the "evolution of consciousness" as such. One idea does not generate another. We grow and, as an expression of a given state, have a type of consciousness,-a "meaning" of that locus which constitutes the "psychic mode" for that stage.

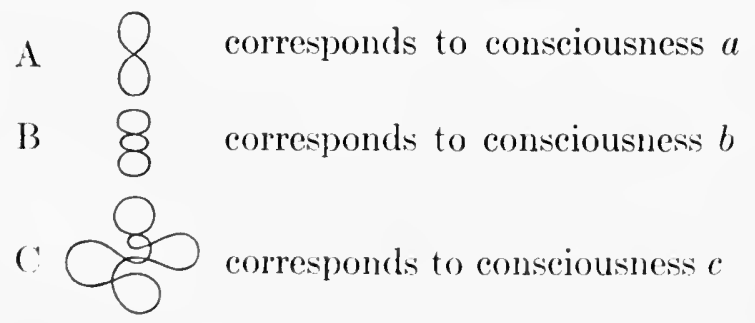

But (a) does not produce $(b)$, nor does $(b)$ produce $(c)$. Or to be more exact, if consciousness is the egocentric (centripetal) 
aspect of the successive phases, each such stage is intelligible dynamically only as a factor in the whole $A, B$, or $C$. Could we properly understand the matter, $A, B$ and $C$ would be but instaneous photographs or "cross-sections" of our life (career), and do not exist as such; and $a, b$ and $c$ are but intrinsic interpretations of that changing movement or transition from $A$ to $B$, etc. To search for the "ground" for consciousness $c$ in consciousness $b$ is like finding cause for a shadow in the same shadow some time before. But the series of shadows $i s$ a reflex and gives us clues-our only clues as to movement $A-C$. And the reaction of $C$ upon other motor-complexes will be quite different from that of $A$ or $B$. 


\section{THE FUNDAMENTAL POSTULATE OF DYNAMIC MONISM}

It was a geniune, if unconscious, insight which dubbed physics, on the one hand, "nature philosophy," and philosophy, on the other, "meta-physics" - an insight which seems to have been to some extent lost or obscured as a result of more rigid specialism. In last analysis it will be found that the present needs in both spheres are identical. What is wanted is a fundamental postulate on which to rear the superstructure in each department. It need not surprise us to find that, after all, this superstructure is one building of many rooms and that the foundation is the same in the two cases.

Such a fundamental postulate must needs be beyond the limits of inductive proof and it can have for its sole credential the criterion of congruousness. Complete congruousness and applicability to the conditions of all experience is all that can be demanded. In all branches of philosophy one of the most serious drawbacks to a satisfactory construction of the data employed is the absence of a common basis of reality-a fundamental postulate ontologically acceptable in all connections

Anyone familiar with modern mathematical physics does not need to be reminded that here too the present need is such a primary postulate. In philosophy students are monists, dualists, etc., but in molecular physics men seem irresistibly driven into monism. It is only when we turn from nature to the problems of subjective experience that the mind doubts the validity of its instinctive craving for unity. In saying this we are not unmindful of the fact that metaphysical dualism is strongly intrenched in the physical pseudo-dualism of matter-force. Yet, however convenient this distinction is, it does not find a place in serious modern physical speculation. 'The reader' who has his "First Principles" well in memory will recall that Spencer frankly recognized the futility of all atomistic conceptions (pp. 51 to 53 , et seq.). He is apparently unable to see any recourse in the crudely expressed dynamism substituted by Boseovich. 
But we turn first to the examination of the more recent results of this speculation, in the course of which we shall not hesitate to avail ourselves largely of the authoritative review of this field by Prof. W. M. Hicks, President of the Section of Mathematics at the meeting of the British Association in 1895. ${ }^{24}$ Dr. Hicks claims that the end of scientific investigation is the discovery of laws and that

science will have reached its highest goal when it shall have reduced ultimate laws to one or two, the necessity for which lies outside the sphere of our cognition. These ultimate laws-in the domain of physical science, at least-will be the dynamic laws of the relations of matter to number, space and time. The ultimate data will be number, matter, space and time themselves.

It would be easy to criticise this statement from a philosophical point of view. Probably the writer, if he had been using strict logical terminology, would have said, "quantity, substance and relation." That the connotation of the terms is that suggested appears from what immediately follows:

When these relations shall be known, all physical phenomena will be a branch of pure mathematics. We shall have done away with the necessity for the conception of potential energy. . . . . . and-if it should be found that all phenomena are manifestations of motion in one continuous medium - the idea of force will be banished also, and the study of dynamics will be replaced by the study of the equation of continuity.

The critical reader will substitute "activity" for "motion" in the above passage, for it is inevitable, logically speaking, that the concepts of motion and force should disappear together. Such a statement from such a source should be convincing of the facts that, first, physical science will not remain satisfied short of a single metaphysical postulate back of phenomena, and, second, that the sole criterion for judging of the claim for recognition of such a postulate must be its congruousness with physical phenomena.

The history of physical speculation shows that the attempts along this line have generally shattered on the predicates of materiality and divisibility. Atomic theories date from the dawn of thought. No one needs to be told that the whole fabric of modern physics and chemistry is based on the atomic theory

${ }^{24}$ Those interested will find the text of the address in Nature, September 12, 1895. 
of Dalton. It is, as history shows, no great feat of metaphysical engineering at times to substitute a new foundation without disturbing the superstructure. The theory of a rigid atom, besides failing to explain the attraction between atoms, was found incompetent to meet the requirements of molecular physics. The luminiferous ether was postulated to meet certain of these difficulties, Farraday's electrical ether to escape others, while MacCullagh's rotational ether attempted a mathematical solution. A rotational ether depends on the gyrations within for its energy. It seems mathematically possible to explain the laws of refraction and reflection by such a theory as the vortex sponge atom, but there are many objections to any form of the vortex theory yet presented, aside from the difficulty of mathematically expressing the form of motion. Thus, the problem of the density of such an atom alone is enough to disturb our confidence in the theory. Maxwell has shown that the masses of atoms on the vortex theory cannot be explained. Lord Kelvin proposed his theory of rigid vortex atoms as far back as 1867 , but it has made little progress beyond stimulating to other similar attempts. The density problem has been simplified by the supposition that, just as a rigid sphere moving in a liquid behaves as though its mass were increased by half the displaced liquid, so the atom has an effective, mass greatly increased by the effect of the velocity on the surrounding medium. Nevertheless we see that an explanation requiring to be so amended is no explanation at all, for we approach no nearer to the ultimate by interposing an intermediary and incongruous postulate between phenomena and the unknown ultimate. J. J. Thomson has shown how vortex rings enable us to understand the laws of a perfectly elastic atom, but no form of vortex atom has yet offered a satisfactory explanation of gravitation, which is really the crucial point in the discussion.

But we must not forget that, as already stated, all these theories require an elastic ether, or, as Dr. Hicks himself admits, "a primitive perfect fluid." However, I am assured by a wellknown mathematical physicist in a recent letter that it is still considered that the ether is not imponderable, but has a certain small weight. If so, it follows that ether cannot be perfectly elastic and our search begins de novo.

Now, the one thing that seems evident in the maze of conflicting 
speculation is that the predicate of materiality has no place in the system. The theoretical "primitive perfect fluid" is not matter-it is not force, but a form of activity whose necessary attribute is spontaneity. Such activity we have proposed to call "pure energy," ignoring for the time being the conflicting usages of that term, and it is claimed that the postulate of spontaneity is no more unthinkable than any other universal. Undemonstrable it certainly is, but it fulfils our one necessary condition of congruousness.

If it appears that spontaneity is logically inharmonizable with the attribute of resistance, we admit that it is indeed destructively so, but when energy is transformed into conflicting, or rather interfering, modes, force is generated, whose very essence and measure is resistance and whose laws have already become familiar as various equations of this resistance. Every instance of transformation of force involves a reconversion to energyan equilibrium of any kind removes resistance, and energy emerges with its own peculiar attribute of spontaneity.

We submit that when the idea of a perfectly elastic medium is substituted for by that of pure spontaneity the difficulties largely disappear. Gravitation, inertia, and, in short, all so-called properties of the atom, are products of the equilibrium of forces and the energy liberated. Change of direction is inexplicable upon the theory of the conservation of forces; but if we recognize the liberation of energy in the moment of equilibrium, and introduce the element of spontaneity, the difficulty disappears. It is confidently believed that, given spontaneity, or pure energy, as the fundamental concept, the domain of physies (becoming, as it does, the doctrine of resistance or tensions) has a clear field for the attainment of the goal which Dr. Hicks points out. All on the hither side of energy belongs to physics; all on the further side of the transformation to energy is metaphysies.

Empirical psychology as a branch of physics deals with the interactions of forces, but speculative psychology is not restrained from imagining the nature of the spontaneities back of the phenomena. The prominent mathematician already mentioned writes:

I am willing to accept the hypothesis that the so-called properties of atoms, etc., are immediate and direct manifestations of divine power which created and now upholds them and that the unchanging character of natural law may be as much a necessity of that manifestation as 
holiness, love an 1 mercy are, for the essence of divina manifestation would have to be perfect good faith anl certainty of action. Due responsibility could hardly be laid upon mankind as moral beings without the conservation of energy, etc.

This passage from a familiar letter is quoted as showing that it is impossible to divorce physics from higher problems. Yet it may not be amiss to seek further construction of this immediate divine in the atom. Whatever it is, it is also the element of final reference in every field of inquiry, as much as in physics. That it may and does possess many forms of manifestation is obvious; one characterization serves for all. It, if divine, is unconditioned ${ }^{25}$ - spontaneous. If anyone objects to the use of the word divine as ambiguous, the same conclusion is reached if we substitute the word "absolute." If disposed to eling to a homogeneous ether-"a pure fluid"-its necessary attributes are continuity and elasticity. Perfect continuity and perfect elasticity, however, require two postulates, $i$. e., unconditioned energy and infinity-both attributes of our postulated absolute. If the latter attribute be denied, we must ascribe limitations to ether, thus conditioning its elasticity and destroying its continuity. Objection may be taken to the introduction of the spatial idea. We admit its incongruity. We did not introduce it; but, if it be carried to its final issue, it destroys itself.

Again reverting to the necessities of our thought, it is claimed that pure spontaneity is the most natural view of phenomena and the earliest. The child perceives movement or change. It is yet to be shown that he necessarily sets up a predicament of eause. Motion is at first an event by itself as much as (and before) an object is. Motion is first observed; change is the primary psychical element and always remains so. It is just as probable that the child sets up a predicament of materiality as of cause in connection with its earliest experiences. In later life, even, our instinctive apprehension of ehange is of something spontaneous, as when we wateh the changing hues of the sunset sky. Logical necessities growing out of the permanence of certain relations lead us to read cause into experience at a later period. We are not denying the validity of cause as a partial eoneept, but simply limit its applieation. What is now needed is a return to the naïve 
method of thought which accepts change as the expression of spontaneity. So only can we conceive of the operations of pure energy and universal will.

Respecting the atomic theory in general, we may say that it sustains much the same relation to the science of energy that the theory of number does to the science of quantity. The mathematics of number is of great practical convenience-is, in fact, an indispensable tool under our present limitations; but the student of higher mathematics feels that it is an inadequate, if not erroneous, makeshift for dealing with quantity as discontinuous while all quantity is really and logically continuous. So with atomic theories; they may be quite indispensable in our attenipts to express the forms of kinetic manifestations, but they are all inadequate by reason of the necessary implication of discontinuity. This weakness is revealed in the fact that it has been found necessary to supplement the atom by a postulated pure fluid in which the atoms are supposed to be bathed.

When claiming continuity as an attribute of energy, of course it is not spatial continuity nor precisely temporal continuity that is meant, but kinetic or dynamic continuity - an idea already familiar to students of Lotze.

It must be left to mathematicians to decide whether the properties of activity can be construed on this basis; but we suspect that the successful solutions of problems of molecular physics will be found capable of conversion into terms of the equation of continuity.

It is true, and no disparagement, that dynamic monism is not novel--in fact it is fully as old as Heraclitus, at least. It may seem a little singular to those who know Coleridge only as a poet to discover that he was the first to clearly enunciate this doctrine in England, but that such was the fact appears in more than one passage, as witness the following:

Space is the name for God; it is the most perfect image of soul, pure soul being to us nothing but unresisted action. Whenever motion is resisted, limitation begins - and limitation is the first constituent of body; the more omnipresent it is in a given space, the more that space is body or matter; and thus all body presupposes soul, inasmuch as all resistance presupposes action.

For some time past monistic thinking has been content, in England and America at least, to rest satisfied with a form of analytic 
monism such as that proposed by Fechner, which represents body and soul as two aspects of one reality, employing the wellworn but specious comparison between the inside and outside of the same curve. The illustration serves very prettily to show the illusoriness of such distinctions, for the outside and inside of a curve are expressions disguising a whole world of foreign implications; as, for example, the relation of the curve to some arbitrarily chosen locus and the simultaneous relation of two other points which are also observers or reference data-in. short, the pretty illustration involves the whole machinery of descriptive geometry, without which the meaning of "aspects" would disappear. In precisely the same way the illustration when carried into psychology implies a complicated system of ontology thinly disguised under an apparently naïve appeal to experience. Returning to the illustration, the only idea of curve suited to the conditions of our problem is that which regards it as a trajectory and discovers in it the equation of force and resistancespontaneity and limitation. At this point the idea of resistance inevitably gives trouble, as it always has and always will. On this head it is sufficient to note that unity of source of energy does not necessarily imply unity or monotony of form. Energy as infinite can but be self-limiting. The self-limitations of the Deity are ipso facto creative, $i$. e., creation is the translation of energy into force.

Quite recently Professor Ostwald of Leipzig has appeared in the field as a champion of dynamic monism and has effectively presented its claims in an address at Luebeck which may be familiar to most through the translation which appeared in "Science Progress" for February, 1896. He said:

"If it [the mechanical construction of the universe] appears a vain undertaking, ending with every serious attempt in final failure, to give a mechanical representation of the known phenomena of physies, we are driven to the conclusion that similar attempts in the incomparably more complicated phenomena of organic life will be still less likely to succeed." "We must give up all hope of getting a clear idea of the physical workl by referring phenomena to an atomistic mechanics."

In the opinion of the writer, we shall never make much progress in the interpretation of the fundamental nature of consciousness and its correlates until we frankly recognize a dynamic principle underlying the whole. ${ }^{23}$

${ }^{25}$ ('f. "The Pasing of seientific Materialism," The Momist, Junuary, 190). 


\section{PURE SPONTANEITY}

Distinctly Lotzean in its derivation though not in its immediate formulation, is Professor Herrick's doctrine of pure spontaneity. Activity or energy, he says, is the fundamental category of experience. Reality consists in the standing in relation of things and this relation is dynamic. Realities are not simply thought together; they work together. ${ }^{27}$ The earliest method of intuition or knowing is also the most accurate. It consists in the recognition of action or change, that is, a doing, as the fundamental fact of experience.

The very simplest concept of reality and the first to develop in the mind of the child is pure spontaneity from which it is the work of all later education to drive him as far as possible. The child is near the appreciation of the "Absolute" as heaven is near us in our infancy. To the child the trees just wave of themselves and he recognizes in himself similar spontaneity; but when the idea of cause is introduced it is quite as likely that the child will think of the trees causing the wind to blow as the reverse. Causality is imperfectly understood energy.

Later life is so sophisticated by the interpretations of the experience of life that language has but few relics of the primitive idea of being as simple action, as in the expressions, "it rains," "it blows," and these are mostly cases where the application of the idea of special causes is difficult or has been late in arriving. To the child "it mews" and "it barks" just as, in the language of the savage, "it thunders." We begin, as the child does, with the fundamental conception of activity. When, if ever, we are able to say something definite about the hidden ground or reason for change it will be time to speak of the thing that acts.

Our knowledge of the existence of things or events is due to changes in consciousness, $i$. e., to activities. All we know of the external world is in the form of changes in our being. It is true

${ }^{27}$ Cf. "The Dynamic Concept of the Individual," Journal of Philosophy, Psychology and Scientific Methods, vol. 1, 1904, p. 377. 
that the technical jargon of science, as well as everyday language, seems to imply the existence of what are called material units or atoms. Modern molecular physics, however, has found that the attempt to analyze the nature of such units destroys them and is returning to the naive concept of childhood that forces simply are, and require no separate explanation of their "areness." In other words, the tendency in physics is to identify being with activity.

Ontology has not been more happy in its search for "substance" - the metaphysical somewhat that stands under and explains all being. This search may be frankly abandoned as futile, for it has not proven possible to avoid a final admission that the ultimate cause of all being resides in the purely spontaneous activity of an absolute Being and nothing has been gained by ages of dialectic in the effort to interpose various steps between this force or activity and its expression. It is better therefore frankly to admit that human thought can go no further than to assume the existence of such a spontaneous activity as the source of being, and accordingly bend our efforts to the task of attempting the analysis of the form and mutual relations of the several expressions of this energy.

Modern molecular physics and chemistry as expounded by such men as Lord Kelvin and Professor Ostwald throw into strong relief the insufficiency of molecular hypotheses whose postulates require one to accept at one and the same time the doctrine that force is inseparably associated with material elements and that these elements are capable of acting upon one another over unfilled space, or that the same imponderable ether is capable of conveying infinite quanta of forces without offering resistance to moving masses of matter.

It is not true that matter and force are in perpetual partnership, one being passive, the other active. Modern science knows of no such thing-can conceive of no such thing-as passive matter. The properties of matter by which alone it can be known are all forces in action. Impenetrability is an expression for molecular bombardment of opposing force. Energy is the one permanent indestructible element in our thinking. It is claimed that matter is indestructible, but this merely means that when, for example, the various forces whose common name in our nomenclature is gunpowder change their form, their exact dynamic 
quantum may be detected in other states of aggregation. The periodic law of ehemistry suggests a rhythmical association of those forces associated with what we call elements and points to a common basis for all these forces. 


\section{HISTORICAL SETTING}

There have always been those who apprehended being thus simply-Aristotle is the first of the Greek philosophers to grasp the dynamic element in ontology and it is even with him only imperfectly and at times contradictorily expressed. $\mathrm{He}$ is sufficiently under the influence of the natural philosophers to cling to the fourfold division, even when it had no significance in the system. In like manner the dualism which appears in Aristotle's classification is purely formal and is a dualism of method and not of reality. Form (eidos) is essence and that alone which can be truly said to be. Matter has only a relative reality as a potentiality in the essence. The thought seems to be very like that expressed by the writer that energy self-limited is creation, or spontaneity is transformed into terms of the universe by the introduction of resistance. Relatively, says Aristotle, matter is non-existent. It is the opposite of entelechy or Aristotelian form which is, as Goethe calls it, the That or actus. The idea of pure matter is an abstraction. He shows great scientific insight in adding that form is at once form, end, and moving cause. That is, form is a determinant based on activity-it is the form of the activity which causes the form of the substance. Motion is the passage of the potentiality (of the energy) into reality. Aristotle's actual cause is a pure dynamic spontaneity. The first mover must be, he says, one whose essence is pure energy, since, if it were in any respect merely potential, it could not unceasingly communicate motion to all things; it must be eternal, pure, immaterial form, since otherwise it would be burdened with potentiality. Being free from matter it is without plurality and without parts. It is absolute spirit which thinks itself and whose thought is thought of thought. This cternal prius is evidently spontaneous and self-actuating and the essence of his being can only be energy. He clearly recognizes the doctrine of immanence and yet the resulting idea of design is limited by the obstacles offered by matter. Remembering the definition of matter, we see that the limitation is inherent in the realizing of the potential, that is, it is a self-limitation essential to the 
expression of the universal in terms of the individual. In like manner the soul is a spontaneity in so far as not trammeled by its setting. As the entelechy of the body, the soul is at once its form, its principle of motion, and its end.

In later times Thomas Aquinas is the first to reiterate the position of Aristotle, but with reserve by reason of the influence of the church, to whose authority he bowed in matters of apparent discrepancy. God exists as pure immaterial form, as pure actuality, wholly free from potentiality. It is plain that the phrase "free from potentiality" means that the inherent energy is pure spontaneity and non-conditioned, for it is added that he is "the efficient and final cause of the world."

"Ea res libera dicitur, quae ex sola suae naturae existit et a se sola ad agendum determinatur."-Spinoza. The true idea of freedom of the will lies in the absence of or inability of external coercion to prevent the expression of the nature of the free subject. Spinoza is evidently greatly indebted to Aristotle. Yet he loses much of the cogency of the older writer by failing to make the dynamic element explicit, and by a spurious mathematical form. He says, however, "God acts only according to the laws of his nature, constrained by no one, and hence with absolute freedom, and he is the only free cause." As a cause God is immanent.

In Leibnitz the dynamic element is fully recognized. Active force is the essence of substance. The doctrine of monads adds obscurity rather than intelligibility to a grand concept. The energy which is the essence of monads is intelligent and where the force is equilibrated or reflected upon self the subject becomes conscious. The principle of continuity necessary to any system of nature is derived from the concept of motion; but in reality it is not motion but energy which constitutes essence and it is this alone which remains constant. Extension is not predicated of the monad and position is only used in an illustrative way. Activity and limitation are the elementary conditions of individual being.

Lessing elaborates these ideas and says that thinking, willing and creating are identical in God.

In Herbart the dynamic element is most clearly developed and it is to this fact that Herbart's utility in pedagogy is chiefly to be ascribed. Herbart says that the soul is a simple, spaceless essence, of simple quality. The intellectual and in fact all psychical phenomena are reactions in opposition to disturbances. 
(He might have added, of equilibrium.) When several such responses arise, they fuse (again in equilibrium). The soul's acts of self-preservation are ideas. That is, the form which the pure spontaneity of the soul takes in returning to equilibrium from impact or limitation is intelligent.

Maine de Biran among later French philosophers most clearly formulates the dynamic position.

"Effort made by the will and directly perceived, constitutes the ego, the individuality, the primary fact of the inner sense." "The idea of force is the corollary of that of effort." "I will, I think, therefore I am . . . I am not a vaguely thinking thing, but a definitely willing thing, which passes from will to action by its own energy, as it resolves within itself or acts beyond itself."

The idealistic mysticism here needs to be qualified by an explicit identification of being in general as action and a proper recognition of spontaneity as a function of all unconditioned effort.

The unfortunate polemies of Schopenhauer have blinded many to the force of the masterly argument in his World as Will and Idea; and many read the poetry of Coleridge without penetrating through the wordy husk to the philosophic truth it seems to obscure rather than reveal. Schopenhauer says, for example,

"The true being of matter is its action, nor can we possibly conceive it as having any other meaning. Only as active does it fill space and time." "Cause and effect thus constitute the whole nature of matter; its true leeing is its action."

Goethe, who was a dynamic monist so far as he was a philosopher at all, recognized that "Im Anfang war die That." 


\section{ENERGISM : THE FUNDAMENTAL PRINCIPLES OF DYNAMIC REALISM 28}

Energy we define as the pure spontaneity of activity, while force is the same activity under limitation, as we meet it in our experience. We have to do with force and postulate energy only on grounds of logical necessity. Common sense revolts at the idea that the objects about us are not real, and the position above indicated is easily misrepresented as though it were maintained that there is no such thing as a real being apart from the process in my mind which brings it into consciousness. We are assured of the reality and objectiveness of the stone wall because of the uniformity of our experiences and the conformity of the testimony of others. What we deny is that the reality of the stone wall is any greater for adding the undemonstrable idea of material elements in the wall. Certain forces acting with uniformity in definite relations form the only basis of reality which psychology or physics can afford.

Experience is a name for the changes which take place in our conscious selves. There may be many changes in the surrounding world and in our very bodies, but none of these is a part of experi ence until it has made itself consciously felt. Changes in our brains and in the current of our physical organism otherwise may produce alterations in the subsequent course of consciousness; but only when these conscious alterations actually appear can they be said to have entered experience. The most careful analysis which physics has been able to make of the phenomena of the physical world has resulted in nothing more than the discovery of a great variety of forces operating in the field of our experience. Force is simply a name for anything that affects experience. Comparatively few forces are thus known directly, but in most cases the force is inferred from the interpretation of indirect effects of forces on experience. We may think of the rays of light impinging on the retina as forces directly affecting

${ }^{28}$ Cf. "The Passing of Scientific Materialism," The Monist, January, 1905. pp" $46-84$. 
experience and of the light rays gathered by the microscope as instances of forces indirectly affecting experience. A moment's reflection, however, will convince anyone having the slightest familiarity with physiology that the first instance is a case of exceedingly round-about affection of consciousness; for the refraction in the lense and the phenomena of accommodation in the eye are but the first steps in an extraordinarily complicated process before the forces can reach the organ where they are said to "enter consciousness." We see then that the organs of sense are simply devices for so adjusting the forces of the surrounding world that they shall produce definite and specific kinds of experience. All scientific apparatus is simply added apparatus with which the ingenuity of man has supplemented the original natural endowment.

The organs of special sense are adapted to cause the experiences that come to us through their mediation to appear externalized. Recent experiments show that a person who wears glasses so adjusted as to invert the field of vision will soon come to see the world as before, right side up, proving that the conception of position and relation in space is due to a reaction between the experiences of the various organs of sense and that is it not a direct "intuition." Experiences which reach consciousness through other channels do not have this peculiarity of external reference and seem to belong more directly to us. This distinction is not a primitive one and to a man born blind who suddenly receives his sight the visible world seems to rest on the eye just as the felt object rests on the finger tip.

The distinction between subjective and objective arises very early, and becomes a most important element in psychological analysis, but it must not be allowed to prejudice one in the belief that there are any kinds of force known to us otherwise than the simplest forms of experience are known, $i$. e., as affections of consciousness. Those forms of force which appeal to us through the avenue of more than one sense with special constancy and acquire the element of localization have attained in our experience a very special coherence and reality, so that the appearance of one of the data from a single sense suggests or revives the data from the other sense and the feeling of reality remains. This reality is thought of apart from the sense data and gives rise to the idea of substance or a reality bencath and supporting the 
appearance. This same reality-idea when applied to the acts that are recognized as such and are plainly forces rather than objects is termed cause. When the reality idea is applied to experiences that prominently affect the sense of touch so that the tactile or muscular sense-element preponderates, the substance is called matter. No doubt the most of us recognize matter in forms of experience in which we have not appreciated any tactile element, but these are refinements of a sophisticated science.

One great gain from this form of apprehension of reality is found in the removal of a problem which has perplexed thoughtful people during the entire past, namely the property of inherence or the peculiarity of one real being which enables it to act on another. If activities are a single essence and differ only in form, they are convertible and thus any form of activity may conceivably be transformed into another and the conversion of one mode of action into that mode proper to my conscious state is a problem of interference or composition of forces, and requires no outside element or tertium quid to "cause" it. A rainbow in the heavens is not less a real thing than the mountain beyond it because the forces acting in the former case are evanescent and appeal to but one of our senses.

A thing or object is a concept involving, in addition to the element of reality, quality or perceived relation and the act of predicating on the part of the percipient. An object implies a subject who posits it (Lotze).

At this point is the critical stage in the development of a congruous theory of nature. Science having primarily to do in the early stages of its development with ponderable things, was founded on the idea of matter in which the forces with which it really deals were supposed to reside as properties. When these properties are removed what remains? To this question science is and ever must be dumb and makes appeal to philosophy. The rash student who ventures to doubt the reality of matter is metaphorically (if not actually) offered the knock-down argument of having his head thrust against a wall. This proves the relative impenetrability of the wall. But the modern physicist himself has questioned the sufficiency of the old position and discovers that this "property" of impenetrability is after all but the resultant of the composition of a vast multitude of molecular vibrations or forces of which we are not cognizant in their individual 
capacity. The question which arises at once is, "if there are motions, motions of what?" But this is, as we have seen, perhaps simply the begging of the question. Is there any reason why a vibration must be a vibration of something? We learn of vibrations which pose for a time as essential properties of some portion of matter being transferred to some other portion of matter and there becoming properties of that object. Evidently this is a region of great obscurity which would be greatly simplified if we could think of the force as the essential "substance" and confine ourselves to the task of tracing its transformations. This in fact is the present tendency of molecular physics, and atoms and molecules are soon to be recognized as convenient words to express states of aggregation of forces. We shall proceed, so far as possible, from this point of view and in speaking of matter and organs, distinctly disavow the implication of reality in matter as apart from the expression of forces which constitute its "properties."

In like manner, we shall seek no special definition of "cause" as distinct from the force. It is the nature of force to act and a non-acting force is non-existing force. A force can be altered but not neutralized. The search for the cause of a certain event is a tracing of the genealogy of its forces.

Science has shown with a great deal of probability that forces are all convertible without loss. There are many facts which seem to show that the persistence of matter is relative and that the serial or periodic arrangement of the properties of the series of elements are hints of the dynamic progression of which they are the expression.

The physicist says he can "get it all back" without loss. But respecting transformation of energy Dr. Magnusson ${ }^{29}$ finds that the old formulæ (all including mass with its matter implications) directly contradict the conservation of energy and introduce time-elements in electro-dynamic equations where they manifestly do not belong. His results materially strengthen the dynamic view; he cuts matter out of the dimensional equations, substituting for it energy in every case, with results which are very suggestive.

20 "Dimensional Equations and the P'rineiple of the conservation of Energy," Journal of Philosophy, Psychology and Scientific. Ucthods, vol. 1, no. 12, June 9. 1904, pip. 316-320. 
The final stage in synthesis is the recognition of the incompleteness of the concepts of matter and force and the determination of the ground of force in pure energy. It is on this last step that dynamic monism is based. The doctrine of pure energy is not and can never be based on observation. It sustains the same relation to metaphysics as that sustained by the metaphysical concepts of inertia and ether to physics of force and matter. As a pure postulate it must satisfactorily fit and explain the observed facts and must leave no incomplete synthesis. We believe that, properly understood, the postulate of energy may serve to remove the hiatus existing between the physical and metaphysical sciences.

Anyone familiar with physics will admit that no construction of matter and force is satisfactory. The two are made to play into each other's hands in a very illogical way so that, at one moment, force seems a property of matter and, at another, matter appears as a product of equilibrated forces. Neither accounts for all the phenomena so that it is necessary, on one hand, to postulate ether which abrogates the properties of matter and, on the other, to associate with force inertia which has other characteristics than force is supposed to possess. Neither matter or force is directly presented and neither is self-evidently conceivable. We have become familiar with the terms and they perhaps have come to seem simple concepts. We are led in physics to the idea of completely elastic media, but this is obviously inconsistent with the supposed properties of matter. We should substitute the idea of pure spontaneity. If it is objected that it is not conceivable, we reply that, strictly speaking, all of that class of predicables are inconceivable. Activity not residing in matter and not subject to the limitations of force becomes conceivable, if at all, just as matter and force have, by construing the relation to phenomena. The concept of pure energy-of action devoid of resistance-is necessary to the proper explanation of physical phenomena as well as the so-called metaphysical.

Philosophically the ultimate is existence (being). From the phenomenal point of view the ultimate is activity or pure energy. The two may be identified. Energy and being are one and the same. Look at the physical side. A purely elastic medium is a postulate rendered necessary by the phenomena ot radiant force. In like manner the phenomena of continuous psychical 
life require the postulate of pure spontaneous energy. Again, let us enquire what phenomena are thought to require pure elasticity in the ether. They are phenomena of propagation, e. g., all ponderable substances transmit various vibrations at rates depending, among other things, on the elasticity of the substance. But the rate of propagation in the "unfilled spaces" bears no relation to such elasticity. It is necessary to assume that the medium is perfectly elastic but is more or less modified by the admixture of an imperfectly elastic substance. Now we submit that upon a dynamic theory this difficulty disappears. We substitute for density, resistance and for elasticity, spontaneity. Under certain conditions of interference or resistance, forces pass from antagonistic equilibrium to concordant phases. Resistance (the criterion of force) disappears and unconditioned energy appears. This energy has no such temporal limitations as force has, and the result is the same as is conceived in the case of a vibration in a perfectly elastic medium.

It would be interesting to trace the application of a dynamic theory to inertia and allied problems, but we notice one other point. When two moving elastic bodies impinge, the bodies suffer an alteration of their course and pursue the new path with unaltered velocity. No force has been lost, nothing has been gained; yet the whole fate of the bodies is changed, and their relation to the environment Here is something from nothingan unthinkable proposition. What is it that has produced the great change. Change of direction or position is a very real thing. It is unnecessary to take into account the molecular changes. Let the two bodies be molecules if preferred. Again, if a bell be struck by a hammer it gives forth a tone and the force is, let us say, all employed in the process. The tone will depend on the figure and structure of the bell. Whatever it is, it is a different form of force from the blow. All the force is returned, but what produces the change? 'The fact of change is the paramount one, yet it is unexplained. Force is transformed without loss and might be collected again; then what is the essence of the change? Our answer is that every change of foree is a death of force. Force can only change by passing through its precondition-energy-and in passing t? rough it obeys new laws. That which physies would fain explain by an appeal to elastieity is better explained by the idea of pure energy. The natural 
condition of being is free unimpeded activity. Now think for a moment of two equal forces in a state of antagonistic equilibrium. Force is not a state of matter, though a state of rest is undoubtedly an instance of hostile forces. A state of rest is not a state of inactivity. In such a state of equilibrium as we have supposed there is a constant escape of force-equilibrium is only relative. But theoretically there is an instant (not of time but of state) when all resistance is removed and the two forces are annihilated as force. They are then replaced by energy, pure spontaneity. This passage through energy is, we believe, the sine qua non for the transformation of force. When a tower is held in place by gravitation, there is a constant transformation of force. One form in which the force issues is inertia or resistance to change. Such inertia shows that energy is continuously being converted.

The concept of ether reduces under strict analysis to energy. The laws of elasticity, which Maxwell assumes are not those of ordinary matter, may be taken, in so far as they go, as descriptive of the nature of energy. This is the perfect liquid of Kelvin. Hinton says:

It can be proved that it [this elastic ether] possesses the properties of a vortex. It forms a permanent individuality. . . . . The consideration of four-dimensional rotations shows the existence of a kind of vortex which would make an ether filled with an homogeneous vortexmotion easily thinkable.

Vortex-motion may be most complicated and may generate high degrees of independence and give rise to properties which cannot be represented in terms of molar motion. This type of equilibrated motion has its highest expression in forms of consciousness. Intrinsic, as contrasted with extrinsic, phenomena belong here. The higher $(4-\mathrm{N})$ dimensions are non-molar and intrinsic. 


\section{THE POSTULATE OF RESISTANCE}

Energy is known and can be known only by its form or mode. Behavior is the thing. Dynamic realism definitively abandons the search for the unknown ground of behavior and claims that for any human philosophy the activity itself is the ultimate. ${ }^{30}$

But this energic form or mode may be viewed in two ways. All activity in a world of reaction expresses itself in two classes of modes, one of which we may call intrinsic, the other extrinsic. This is the direct result of a law, which is clear enough from the popular side, but has hardly been sufficiently appreciated in philosophy; namely that activity is meaningless without resistance. Any expression of energy in a universe is dual in its manifestation. We could perhaps imagine, or at least, speak about unimpeded energy or "pure spontaneity," which would possess only an intrinsic mode. But its meaning would be for itself alone. No such manifestation of energy is possible. Physically, action and reaction are constantly associated and equal. A single or isolated force is impossible. ${ }^{31}$

Is there difficulty in this concept of "resistance?" Is it that an energy that has no material tag to it and "goes of itself" could not be limited? That seems a little like the idea that because "Father owns a bank he can get all the money he wants" or "Because I have a cheque-book I am forthwith rich." The self-limitation of creation settles that.

However, there is another way of looking at it. In any genetic way of conceiving of a universe any part must be implicated in the whole and the whole in every part. There must be a teleological or rational unity. This would be manifestly impossible if the energy were erratic, sporadic or variable. More closely thought out, the conservation of energy means that the doing that I now perceive is all of it bound up with the doing that was and that is to be. Our measures are all psychological. ${ }^{32}$ So far

\footnotetext{
3" ('f. I'sychological Rerieu, vol. 11, 1904, P. f106.

3 Hhill. p. Hot 40 -

32 sae . Vomist, January, 190.) p. is.
} 
as the externals are concemed, the various forms of force are ineommensurable. There is no way to show that so many footpounds $=$ so many calories. All that we mean is that these cohere in a system in such a way that such and such phenomena in one domain result from such and such transformations in the other. If twice as many foot-pounds had been found to equal the calories, we should have been in no way surprised. The point is that all energy is related to all other energy: there is an organism.

The question might be asked (in fact it has been asked) $:^{33}$ "How is it possible to get the resistance or limitation necessary for the objects of our experience out of pure energy?". "Is the element of tension and opposition in your very conception of energy?"

The reply to this should be based upon an examination of the nature of the energy concept more detailed than is germane to our present purpose. The difficulty is, probably, like nearly all philosophical perplexities, a result of our unhappy logical faculty for splitting things that ought not to be divided. We may undoubtedly think of the word, "doing," apart from the expression, "doing of something," but it is to be doubted whether we can think of pure energy at all. We think by "affirming attribute." It is still more energetically to be insisted that no real severance of the doing from the thing done is permissible. It is the old matter fallacy or the cause-effect fallacy in a new guise. If energy is to be set up in the place of matter as a power behind the throne let us alone and we will return to our idols.

Viewed from a physical point of view, given no resistance to action, there is no energy. If we mean anything by energy, it must be valid in that it is acting. If the sum-total of universal energy were in like phase, it would be the same as if there were no energy so far as making a universe is concerned. Herbert Spencer has not lived in vain. Pure being is the same as non-being. We have had our Hegel. A non-acting deity would not even potentially be a God.

Practically, energy is called into and remains in existence only under condition of resistanec. Resistanec is varied and gives rise to mode in energy. The writer has defined creation as the selflimitation of creative power. This is not subject to further analysis. Having no experience with universal or infinite modes of

${ }^{33}$ Monist, January, 1905, pp. 85-86. 
being, we do not expect to understand what we must nevertheless postulate. If this view is open to the taunt that we take out no more than we put in and so are no better than prestidigitators, our reply is ready. If other people take out of their logic more than they put in, they lay themselves open to the charge of dishonesty. The taking out of more than is put in is called in logic "fallacy." 


\section{DYNAMIC MONISM AND HEREDITY}

Nearly all writers on heredity in recent times have found it necessary to postulate some form of material vital units as gemmules (Darwin), physiological units (Spencer), pangenes (DeVries), plasomes (Wiesner), biophores (Weismann). These biological units are necessarily regarded as different from the structural units or molecules and composed of aggregates of them. A few authors have, indeed, seemed to identify the biological unit with molecules, but the way in which the concept was employed shows that such identification was due to a confusion of ideas and not to any logical identification of the two elements. It is only necessary to indicate that the properties of molecules cannot rise above the nature of chemical reactions while the biological unit is postulated to explain an entirely different set of phenomena. All the attempts to cause these units to serve the purposes of heredity have served to illustrate the inherent weakness of the concept. Thus when the gemmules were required by Darwin to explain the fact that the germ in some way seems to represent the totality of the organism, he came to the absurd result that, if the gemmules were at least as large as molecules and every cell in an oak is represented in its germ, an acorn would need to be as large a bushel basket, not to mention the curious fact that every cell in every acorn would need to be represented in the germ of every other acorn.

Various forms of corpuscular emanation theories avoid this absurdity only by falling into others. Even if a fundamental distinction is made between somatic and germinal elements and a continuity of germ-plasm alone is demanded to explain heredity, the problem is not rendered more intelligible, while it must be admitted that facts seem to prove conclusively the educability of the germ. The phenomena of everyday experience tend to show that the organism is a whole and that the germ up to a definite point in its history is as much a part of it as any other cell or organ.

The solution offered for the problem of heredity by dynamic monism is as follows: The individual is a composition of cyclical 
forces equilibrated in a vastly complicated aggregate of interdependent series. As in other cases of equilibrated forces there is a nucleus of energy which may be regarded as the real being of the individual. This nucleus grows out of the fact that forces in equilibrium are constantly changing and each change involves a passage through a state of removed resistance when spontaneity or pure elasticity emerges. So far as the energy is in harmonious phases we have a unitary development; so far as these conflict resistance occurs and force is evolved which adds to and modifies the equilibrium of the whole. The constant tendency is thus towards perfect adjustment of the energy, and this is accompanied by a constant change in the force-complex.

Every new influence (environmental) affects first the equilibrium of the adjacent force aggregates $(i$. e., those of similar sort), but the change must then affect the equilibrium of the whole. The form which this change may take depends largely on the form of the existing equilibrium, so that no reaction of the environment can fail to cause a readjustment of the whole. When an organism, for example, passes from a warm to a cold climate it is not merely the integument which is altered but the whole organization is readjusted. This corresponds with what Roux means by a "struggle of the parts." From the point of view of dynamic monism such a struggle is inevitable; the balance of the organism is so delicate that no touch anywhere can fail to modify the whole. Now the germ so long as it still forms a part of the organism and participates with it in nourishment, ete., is more or less implicated in the readjustment. If we conceive the equilibrium of the organism in the form of vortex-motion, for example, it can be understood that when symmetrical partition of the figure of motion occurs for any reason, the two resulting vortices will be like vortices in opposite modes. The fusion of two such vortices would reëstablish the original motion. Minor differences could be overcome and would result in variation in the rate or figure of motion. In the simple case of organic multiplication and conjugation of entire animals this is what actually takes place. When the differences have become too great, fusion is impossible.

Now in higher animals the rortices are multiplex and yet the elements are similar and interdependent. Finally the complexity is increased and only certain rortices retain the typical form and 
reflect the fundamental law of motion of the species. Such are sexual elements.

The great difficulty which has hitherto existed in construing natural selection has been the necessity of discovering some cause for variation. According to a dynamic hypothesis the core of energy constitutes a nucleus of spontaneity or unconditioned activity. The form of expression of this activity will be determined in part by the "structure" of the organism and this is dependent on its phylogeny, and in part by the extraneous impressions (environment). Unconditioned spontaneity has in the course of phylogeny become conditioned by its own past as well as the present of its environment; yet there is the element of spontaneity, and what is to be explained is not why it takes such or such a form or direction but why it does not take any of all other directions. The original unconditioned spontaneity was, then, a tendency to express itself in all ways or, in other words, infinite variability. This variability is no longer infinite in so far as the results of previous activity have precluded many forms of expression. The mathematical expression for the activity of any organism is composed of a vast number of factors mostly too complex for our analysis. Heredity is a comprehensive term for those factors connected with past activities which have modified the figure of present activity. If we could comprehend the expression for the existing activities in any organism we might hope to predict the range of its variability and the effect of changes of environment on such variability, or, in other words, the actual variation.

In attempting to understand the effect of selection one must have regard: (1) to the status presens of the organic activity and its cyclical alterations; (2) to the balance of element with element or part with part which will be disturbed when any new force enters the environment; (3) the direct tendency of that force. For example, a condition of darkness may directly interrupt certain visual processes and alter the circulatory and nervous equilibrium, but indirectly it may cause compensatory changes in nutrition of other organs; or the development of antlers in one part may be correlated with changes in other parts of the integument quite independent of the necessary changes in muscular control due to the added weight. In such matters as the formation of color-patterns this law may be very important. 


\section{DYNAMIC APHORISMS}

The point of view of Professor Herrick may conveniently be summed up in the following list of propositions (which, however, it must be remembered were written at widely separated intervals and never revised by their author and might, therefore, have been stated differently today):

1. Existence (being) and energy are identical.

2. Energy is pure spontaneity.

3. Unimpeded infinite energy would to us seem indistinguishable from non-existence.

4. Force arises from interference of energy and implies resistance.

5. The complexity of resistance measures the quality of the foree; the degree of resistance measures the quantity of force.

6. A thing or phenomenon is a manifestation of force to our apprehension and involves a thinking together or synthesis.

7. Substance is a reality or eause posited behind the thing. To the monist this reality is energy.

8. The introduction of resistance is creation. Creation is the self-limitation of energy.

9. The systematic inerement of resistance-hence eomplexityis evolution. There is no creation of energy, only evolution of force.

10. Matter is a subjective interpretation of forces in a state of relative equilibrium-it is imperfect or incomplete synthesis. For human beings this equilibrium must involve at least two of the forces appealing to our senses. (A rainbow is not interpreted as matter because the equilibrium subsists for vision only.)

11. All forces appealing to us in ordinary experience are either directly or indirectly associated with matter, because all these forces tend to equilibrium.

12. Vital equilibrium is the highest common form in which equilibrated forces are presented to sense.

13. Consciousness is the focusing of diverse fores upon the complicated neural equilibrium-an equilibrium of dissinilar forces of a speeial kind, $i$. $e$, the synthesis of antagonistic forres 
into homogeneous energy. It is a complete synthesis rather than a mechanical equilibrium.

14. Will is the energy so liberated.

15. Self-consciousness is the result of resistance encountered by this energy growing out of disparity between the normal modes of subjective energy and the results of the new synthesis, converting it anew into force and reflecting it. Psychologically, that is to say, self-consciousness is the reaction of the will in its expression upon the empirical ego.

16. Will is pure spontaneity in the form proper to the individual nature and is only indirectly in consciousness. As pure energy it is free (that is, to express the real being or character of the individual), but in its expression as force it is conditioned like any other force. What in psychology is termed will is a complex consisting of a variety of conscious elements, - feelings, judgments, etc.,- and sundry impulses with their trains of reflex feeling. It does not therefore obey any simple law.

17. The soul of a finite being is the totality of the energy involved in a conscious being. Its activity is not, as such, conscious. The mind - the "soul" of psychology - is the sum of the conscious manifestations. It is not correct to state that one mental state is evolved out of the preceding, for one act of consciousness has no direct connection with any other. Yet it is true that the mental processes give us the only clue to the sequence of soul processes. The conscious states are epiphenomena due to the constant becoming between energy and force.

18. Removal of all resistance would destroy all consciousness: Nirvana. Perfect equilibrium would make all energy conscious, as there would be a rhythmical alternation between energy and force: Panconsciousness. A soul can be immortal only in a resistant (responsive) medium: Heaven.

19. The greater the complexity of the impinging forces, equilibrium being preserved, the greater the psychical activity.

20. Forms of complexity tending to perpetuate the activity and preserve the equilibrium are pleasurable; the reverse are painful.

21. Personality is the unit of consciousness. Consciousness can never seem discontinuous, because that would imply a second consciousness ad interim.

22. We create the objective world in accordance with forms 
inherent in our subjectivity. ${ }^{34}$ The three fundamental categories or forms of thinking are mode, time and space which afford us the "this-now-here" of experience. This is the psychic present experience. The psychological past and future experience is always a "that-then-there" 3 ;

23. Time and extension. ${ }^{36}$

Time is a pregnant illustration of the tendency of the mind to effect a complete synthesis and to set up an abstraction as a symbol of the synthesis. Time is not given in experience. It is not seen to be the necessary form of inner experience until the synthesis is effected. What we really have is a series of sequences. Time as continuous is reached by the same kind of process as gives us number or quantity as continuous-a late and complicated acquisition. Every possible interpolation in the series of sequences finds the organism receptive. We are not, for example, conscious of our organic sensations as continuous; but, whenever attention is directed to them, they emerge. They are, we conclude, continuous. This is not an immediate apprehension, but a synthetic judgment. Our experience is indeed discontinuous, but various considerations lead us to fill the hiatuses. It may be added that we only incidentally become aware of the discontinuity. What then is the neurological basis of sequence? Something perhaps like the following. Vestige $a$ in cell $I$ awakens a certain interneuritic reaction. Upon this the similar vestige $b$ is superposed without introducing any new reaction. This state affects consciousness in the manner interpreted as identity. Again upon vestige $a$ vestige $c$, which tends to produce a different reaction, is imposed; and this change is interpreted as dissimilarity. The same thing is true if the cortical image be objectively caused and then repeated. If I gaze on an object and after closing my eyes a moment again view it, a sense of identity is produced. If again we superpose upon $a$, which is now a vestigial image, an objectively produced image of the same kind, $A$, the resultant is not pure identity nor is it dissimilarity. Vestige a has not the same penumbra of subcortically produced elements which it has. In the first case the presentation is $O$ and in the second

\footnotetext{
${ }^{34}$ P'sychological Review, vol. 11. 190t, p. 401.

${ }^{35}$ Journal of Philosophy, Psychology and scicntifir Wethods, vol. 1. 190-1, p. 373.

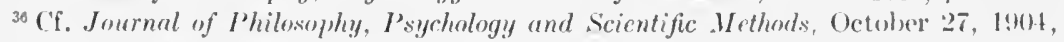
p. 602; and Monist, January, 1905, 1) 79.
} 
$\mathrm{O}+x$. The dog whose vestigial image is repeatedly revived is not conceived of as a series of dogs or the same dog at different times: it is simply "that dog;" but if the dog comes into my field of view, it is the same dog seen again or recognized. If I view an object in motion, it may produce one of two effects: if it passes too rapidly to be accommodated for, it produces the effect of changing position without change of time (extension). If the motion is slower, the jerky motion of the eyeball in accommodation produces a succession of images. The hiatus between these images is subjectively filled and we get the concept of continuous motion. The modalities of presentation here noticed are, then, (1) position (the act of positing), (2) absence, (3) recognition, (4) distinctness, (5) succession. In the higher sphere of judgment these become (1) existence, (2) negation, (3) identity, (4) difference, (5) time. The difference between the two categories is that one has a particular the other a general application.

A synthesis of a visual impression gives us position (place). A synthesis of several places having an identical content gives us the idea of extension and thence figure, etc. The final synthesis results in the universal-space. In time the vestigial predominates; in space, the objective. Both are, in a sense, the necessary forms of our thinking, but the necessity is not an inexplicable or arbitrary one. It inheres in the nature of the presentative process and the synthetic necessities of thought. It may not be necessary to illustrate further. We have gone thus far into detail simply to indicate the way in which the dundamental postulates are applicable to the problems of psychology and metaphysics. Everything could not be said in any one of cases cited. Enough has been said to show what further use could be made of the idea of energy.

Psychologically speaking, space is certain stresses and strains, certain tensions in the effort to move. It is a question of position with respect to my organism as a center. Ourprimary experience of space is angular.

Visual, $i$. e., retinal, space is in two dimensions. Such space is closed. Our visual life is in one surface only. The eye does not shoot forth visual tentacula in search of the object as the ancients supposed.

We gain the idea of the third dimension only by going toward 
and from objects. Secondarily we gauge them as they go from and approach us. The born blind, on recovering their sight, seem to lack depth in their space.

The axes of reference, fore-aft, right-left, up-down, are partly gravitational and partly anatomical, and do not express the dynamic standards actually employed by the mind (for example, in the metageometry, with its fourth and even $\mathrm{N}$ dimensions).

Now, says Hinton (in his book on The Fourth Dimension), if some hypothetical plane (two-dimensional) being should be informed of the existence of a third dimension and it were explained to him that a cube could be thought of as a square repeated in this third dimension an infinite number of times, or as a square moving in a certain unknown (to him) direction for a certain period, we get some notion of what the fourth dimension is to us who live in three dimensions.

So in the case of the fourth dimension, there may be a direction normal to all three of the known dimensions in which movement is possible; and, in the absence of the ability to make molar motions in that direction in the ordinary way, we can form no notion of the fourth dimension. It does not become a dimension or spatial element, but must be represented in temporal or intentional terms. Physical research seems to prove that there are "things doing" in nature that cannot be conceived of as done in tridimensional space, and this fact gives zest and meaning to this metageometry.

The metageometry seems to show us that moving to infinity in a radius drawn from my organism as the center of experience would be to return to the starting-point - that going far enough from self as a center would be to return - that is, the radius, after all, is but a great circle of the universe.

We call motions molar which are capable of giving rise to space conceptions. Molecular and intramolecular motions, cohesion, gravitation, etc., do not produce these perceptions directly. If the speculations with reference to vortex activity, which is supposed to give to energy the static character constituting materiality, are to be trusted, we may have in these the elue to the fourth dimension.

24. Causation as such eamnot be defined, because it does not exist in the form of a plurality of eauses. What does exist is such an indissoluble linking together of all realities in fixed rela- 
tions as makes of the whole a complete organism, every part being implicate in every other. The complete organism is the "ground" of all being, and is the only thinkable cause. ${ }^{37}$

25. Reality is the affirmation of attribute. Reality in terms of experience reduces to an affirmation (subjective) of attribute (objective) and the attribute is always a "doing" or activity. ${ }^{38}$

Lotze says:

We cannot make mind equivalent to the infinitive "to think," but feel that it must be that which thinks; the essence of things cannot be either existence or activity; it must be that which exists and acts. Thinking means nothing, if it is not the act of a thinker; acting and working mean nothing, if, in endeavoring to conceive them, we leave out the conception of a subject distinguishable from them from which they proceed.

On the contrary, it is impossible to conceive of a subject distinguishable from its acts or properties. . . . . The doing of things in a constant way or according to some law of action is the most real thing we know of. A modern printing-press with its bewildering multitude of activities is a very real thing, and the most real thing about it is the doing of all these correlated acts for a common end. We may say that these processes are the products of certain wheels and levers. But these wheels and levers produce their result primarily by virtue of their arrangement, the result of activities; and even the properties of the metals, to which in our search for the subject it at last reduces, prove to be activities. In fine, we discover that the printing-press, so far as we can know it, reduces to correlated activities working harmoniously to some intelligible end.

So of energy and matter, "What has our postulated material entity done to it? It has added no matter to it. It has subtracted no force from it. . . . All that remains of our postulated materiality is form of motion or activity. . . . The impossibility of discriminating essence from form or kind of activity. . . The discrimination of essence from attri-

\footnotetext{
${ }^{37}$ Discussed at length in the Journal of Philosophy, Psychology and Scientific Methods, vol. 1, 1904, pp. 596-600.

${ }^{35}$ See Journal of Philosophy, Psychology and Scientific Methods, vol. 1, 1904, p. 377; also "The Logical and Psychological Distinction between the True and the Real," Psychological Review, vol. 11, no. 3, May, 1904, pp. 205-210.
} 
bute is a psychological impossibility. . . And . . essence must include the past and future as well as the present of the thing."

To return to Lotze's quibble, the mind is not equivalent to the infinitive "to think," but is a thinking thing. It would not be thinking if it were not a thing, and if it would not be a thing if it were not thinking. Indeed, it is the kind of a thing it is because of its thinking and the only knowledge we have of a thinker is his thinking. . . . . The tone emitted by a bell when struck is the result of activity, and this tone is also a more or less constant expression of the constitution of the bell.

When I say "Lo, light!" I do not mean "Lo, I recognize light out there as an external reality." I mean "Light, a real effect, is." When I go on to say it is something out there, I have introduced the substance element. This may or may not be true, but so far as light is an experience solely, it has that about it which constitutes immediate reality: self-affirming attribute. Considered $a b$ extra, as a logician, I discover that it is possible to see in this two aspects: (1) the affirming, which is essence according to the old logic, and (2) the attribute or mode affirmed. Neither of these is real, but the joining of these is the essence of reality; it is experience.

Whether Professor Herrick was a realist or an idealist is a good deal the same sort of a question as when asked concerning Lotze. Professor Herrick himself says in one of his letters in reply to a question of this kind:

I suppose I am a realist in the sense (say of Fichte) that the phenonenal world has an existence independent of the mind or that there is at world of existence independent of the mind corresponding to the phenomenal world. I am an idlealist in arlmitting that my world is phenomenal, but I am not prepared to say that being exhausts itself in revealing itself to me as real. I may admit that the sun gives light only to the seeing eye; nevertheless the sun exists as an active souree of the phenomenal and by spiritual parallax (judgment) I may ascertain this fact as true. The idea is not somothing archetypal nor does being exhallst itself in individual reality.

The solution of the molsom involved between realism and idealism seems to be this: Viewed extrinsinally the universe is real; intrinsically, it is illeal. There is nothing in the world that has not a rational basis, and out of this grows the posibility of realizing it. To rod the world is ideal. To man there is a progresisive realization. Our limitations make us realists. We shall be pure idealists only when individual limitat ions disappear. ${ }^{38}$

\footnotetext{
3s (On this question see further, "The Law of fongruousuess amel its logrical Appli-

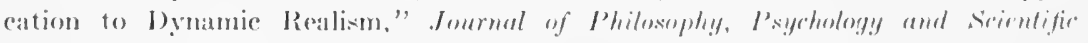

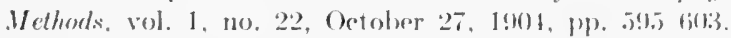




\section{THE FREEDOM OF THE WILL}

Let us examine the matter first psychologically. First, there is the concept of an act. Every vivid concept of action creates or borrows from the energetic side of the mind an impulse to perform the action. A second alternate action is conceived. The mind is, as it were, in suspense. Impulses to one or the other act appear with fluctuating vividness. There results a sense of suspended judgment. The energetic side of the mind is inhibited. We have the feeling of being able to do either. The concept is real rather than an imaginary one in either case. Were the conflict between the concept of jumping over the horse-block and jumping over the moon no such feeling of free alternative would exist.

The inhibition is felt as an internal restraint rather than an external coercion. Judgment having been passed upon the viability of the two impulses, then moral judgment compares the issues of the two acts with the self-ideal. One act will conduce to my physical well-being, the other will not: the one act is good, the other bad. One act will contribute to the greater welfare of the community or of an ideal abstraction ("cause") connoted with self, the other will not; the former act is right, the latter wrong. One act will bring approval of some constituted author. ity to which we owe allegiance, the other not; the first-mentioned act is lawful, the latter unlawful.

On such considerations as these one act is approved and the other disavowed. Inhibition ceases - the impulse to act, reinforced by all the added motives adduced by intelligent consideration, issues in the midst of expensive, irradiative (pleasurable) psychical accompaniments. We have performed a voluntary act approved by conscience.

I am a free moral agent because my acts are judged to agree with the demands of my being or of my character independently of any external coercion.

But was it, after all, a simple algebraic sum of various motives which my mind performed? By no means. It was more like a case of greatest common divisor, the common dividend being my character. 
But could I have chosen otherwise? Yes, but only by violating my own conscience and degrading my own character. That would, however, have indicated that my character was not what I supposed it to be or was not in accord with the ideal self. I could not have done otherwise than I did being what I was. Thus arise the continual antinomies of the real and ideal self. ${ }^{40}$

Here we have a reconciliation of the law of determinism and the Doctrine of Sin. The old Hebrew idea of sin etymologically was that of missing a mark. Sinning is a mistake or failure. The concept of self increases faster than the impulses proper to its preservation. These impulses grow as character grows; but character is always behind a growing ideal, though it may be a long way in advance of a diminishing one.

Conviction of sin is possible only in a growing stage of moral life. A failure correctly to estimate the results of a line of conduct may result in our standing aghast at the results of an unconsidered act, but this does not affect the moral value of the act. Remorse is often but the belated realization of results. Such feelings are educational in effect and are substituted for in society by the punishments which form the sanctions of law. The cultured man suffers more by remorse than from any punishment, but his remorse is not capable of acting as a deterent to others.

If sinning is a mistake, where is the responsibility? Why was the act wrong? Because I now perceive that the act was not performed in conformity to the demands of my ideal nature. We say that my lower nature prevailed; nevertheless nature, since life began, has been building up these very impulses and appetites. These are essential to self-preservation. Our clearer vision now sees that they are but partial. The ideal self is larger, loftier, better. We ought to act in its behest. But, alas, it does not possess the strong body-guard of inherited impulses and requires to be guided by the elearer but colder light of reason.

40 "Everyone regards himself a promi as free in his individual actions, in the sense" that in every given casc every action is possible for him and he only recognizes a posteriori from experience and reflection upon experienee that his actions take place with alsolute necessity from coineidenee of his character with his motives. Henee it arises that evory uncultured man, following his feeling, dofomls his froedom in particular actions; while the great thinkers of all ages, and, incleal, the nore profound

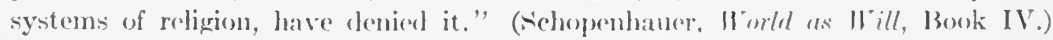


But to whom the larger self has once been revealed, any act carried out at a lower behest than this highest brings a sense of self-degradation and of shame. In spiritual evolution woe to those whose ideal so far exceeds the executive impulses that life becomes but a succession of lost battles!

Two classes are possible, saints and sinners-those who preserve the will to protect the highest self and those who consciously abandon the effort.

The controversy which has raged as to the freedom of the will versus determinism results from a mistaken idea of freedom, complicated by a perverted application of the idea of causation.

As Schelling says:

to be able to decide for A and non-A without any motive whatever would, in truth, simply be a prerogative to act in an altogether irrationalmanner.

Leibnitz says, more bluntly, that to desire such irrational freedom would be to desire to be a fool.

Let us analyze our feeling of freedom in volition. We first must have an alternative, to be, or not to be, to do or not to do, to do this or that. The two acts compared are measured by our powers and adjudicated in this respect. We do not will to achieve what is manifestly impossible. The child but not the man cries for the moon, but the moon is not unattainable in the mind of the child. This produces a sense of alternative. The second judgment is as to the value to self, a comparison of suitability, not of possibility. The essence of freedom is in the idea that $I$ may do it, not that the thing is permissible or may do itself. The idea of uncaused action violates the fundamental thing in our feeling of personal freedom. It is precisely the ego-activity in action that makes it free. The unhindered expression of self in relation to an act or, better, the act issuing in conformity to the structure of self or character constitutes freedom.

The indeterminist ignores the vital element in freedom in the search for that impossibility, an uncaused cause. Cause is an abstraction convenient as a category, but cause can only mean the immediate expression of one being in relation to another. If we conceive of a cause unpreceded by another cause, we deny prior time. Efficiency and being are the same. Even the being of the Absolute Cause, viewed as man must view it in segments, is 
a sequence of causes. When viewed otherwise, as an omniscient being might view it, it is conceivable that the idea of cause would altogether disappear.

The only conceivable kind of human freedom is that which consists in the unhindered expression of self in response to external motives. It is idle to suppose that the ego could go back of self and fabricate a feeling of cause prior to its own being, or construct a mechanism for deciding behind the deciding agent. It is left for deterministic philosophers to imagine such a deus ex machina.

But if it be true, as Tyndall says, that

it is admitted generally that the man of today is the child and product of incalculably antecedent times. His physical and intellectual textures have been woven for him during his passage through phases of history and forms of existence which lead the mind to an abysmal past,

then the ego is not only caused, but it is one of the most complicated webs of causation. With what made me what I am, I have nothing to do; but, being what I am, I am responsible for my acts in so far as they conform or fail to conform to this ego.

Responsibility is the strongest argument against the indeterminist position in its narrower sense. To admit that $I$ am to blame is to admit that the act was chosen with reference to self. To claim that the act was directed arbitrarily by some other power than one's own character would be to absolve the only ego we know from responsibility. 


\section{THE PROBLEM OF EVIL}

Why is evil permitted in the world? This is the great unanswered question in human experience. The only general answer is that of Job and the only recourse is submission to the inevitable.

For any approximate answer it is first necessary to define evil; it may be that, if properly defined, the question regarding evil would not need to be asked.

We know that life is physically over-shadowed by pain. However bright the dawn, few days lack this blighting experience, and many a life is foredoomed to drag out weary years of agony. Nothing is so real as pain. The buoyant youth strives to realize some bright ideal. All are pressing toward the mark of a high calling. But how seldom does our most strenuous endeavor achieve success. Rather, how inevitable is failure in the end. Every man is thrust into life-long conflict with a superhuman foe and acknowledged defeat from the start. Death with its unfathomed possibilities is the portion of us all.

Still again, we are all artists painting, with such skill as we possess, our own portraits. Daily we toil at the growing ideal of self. Hourly the vista of life opens before us and the universe grows large and pregnant with new possibilities. New relations are discovered and our self-ideal adapts itself to new possibilities of reaction.

This almost subconscious activity may be likened to the instinctive assimilation of self to the hero of an interesting story we may be reading. That we do not formulate such a self-estimate is because it is so fundamental a condition of our conscious life and lies as a rule too deep for words and is clothed in that modesty that is the external aspect of self-respect.

But with what a shock do we discover that in the hour of trial our self-hero fails to display heroism! We conceived our self as rescuing the perishing, but discover with shame that in an agony of fear we have pushed to their death those who clung to our garments. We conceived ourself as resenting the bribe, but find the inducement so alluring that we temporize with the tempter. 
We may at last, in utter self-abasement, lay our mouths in our hands and our hands in the dust and pronounce ourselves unclean - the worst of sinners. But if character keeps growing, sinners we shall always find ourselves to be. Nothing is a surer sign of moral stagnation than the smug self-sufficiency which admits no sin. Sanctification and freedom from sin may mark the end of a holy life, for surely further growth is impossible.

Pain, failure, sin; these we call collectively evil. A stone falls on the foot and produces pain. A stone is not evil. Gravitation is not evil. But gravitation acting on a stone may produce in my foot maladjustment of processes not in themselves evil. The circulation and its concomitant nervous processes are physiologically good. It is no accident that wrongly adjusted physiological processes are painful. Natural selection has doubtless brought about this result.

The burnt child dreads the fire; it is easy to say that pain is monitory and so good, but self rebels against it as evil. We perceive that, as pleasure is not good but its usual accompaniment, so pain is not evil but its permanent concomitant. Most deep seated diseases and fatal injuries are not especially painful. Pain has developed where it has a utility to the race.

But, it is said, pain is not a guide to the correction of the evil. True, it is but a voice crying out from nature "Beware!" How our utmost soul goes out in sympathy at sight of a suffering child. We can scarce avoid raising clenched hands defiantly against Heaven and cursing the injustice that causes agony to a helpless and innocent babe.

The voice of the babe is the ery of the race. It speaks to the best in humanity, imploring aid, impelling to research. By and by a Jacob Riis hears the piteous wail of the human child, and iniquitous tenements tumble to ruin or grassy oases arise in the desert of Manhattan, or factories cease to grind out their grist of human suffering.

In a happy world there must be sorrow and pain, and in a moral world the knowledge of evil is indispensable.-Fiske.

Failure admits of a similar analysis. As pain indieates an imperfect adjustment, so sense of failure in the intellectual sphere is the maladjustment of effort to object. If the iron be dull and thou whet not the edge, put to the more strength. Siense of 
failure is the spur which rides a good horse to success. But the goal is ever receding, the success of today is the failure of tomorrow.

He who counts himself to have achieved will train no more and run no more. Let us bury successful men, they are all dead men. What if we must all fail? How many crushed corpses were flung into the trench that other legions of the one army might rush over to victory?

If our self ideal is large enough, we may view life as the hero views death, a mere incident in the triumphant flow of a great "cause." Savage legends picture happy hunting grounds. Mohammed promised his followers paradise and bright-eyed houris. Christian authors have foretold streets of gold and joy unspeakable. Older religions thought it sufficient incentive to right living to look forward to such oneness with the creative Power and directive Intellect that self shall expand to embrace the all-will and the all-purpose. The insignificance of the finite is thus absorbed in the infinite and shares in its fulness.

By such scaffolding has humanity buoyed itself up under the weight of failure. Be it what it may, it is incumbent upon us, as Margaret Fuller expressed it, "to accept the universe," content to believe that while it has not entered into the heart of man to conceive of what awaits the contrite, yet finally we shall be satisfied. And do not snatch away the child's painted toy because it is but a poor image of the reality. In good time he will put away childish things.

Ah, but about sin? Surely there can be no good arising from that terrible sense of defilement which follows recognition of sin. We have seen that, for the old Hebrew, sin was but failure, a missing of the mark. The Greek had little or no idea of sin in our modern sense.

Sin is failure, but of a peculiar kind. Ordinary failure grows out of error of judgment. Our estimate of the effort necessary, for example, was wrong. The object was more remote than we thought. In sin the failure in adjustment is in the citadel of self, the will. The higher self required a certain act, moral judgment approved the act, but recalcitrant will performed another. Otherwise expressed, the ideal self which we pictured, is found not to exist, and the self we loathe is found dominant. The ideal and the actual are conflicting. This maladjustment is most humili- 
ating because in the highest sphere. We could and did endure the pain we could not avoid, we expect to improve on the failure; but "who shall deliver us from the body of this death" in our inner heart chamber, with which we must live sleeping and waking?

I, the soul of honor, brave and true, my life-long hero unconfessed-I a poltroon-a cheat? No, a thousand times no; rather any pain, any failure than this. Even the outer simulacrum of this heroic ego, the man we hope others think us to be, is worth dying to preserve.

No wonder that any charlatan can gain followers if he can but persuade them that he can deliver them from sin!

Sin, the supreme failure, the extreme of pain, the crime of the traitorous self-can this also be a concomitant of good? Certainly it must be so, for no single human being has been without it.

So long as the disparity between the ideal self and the self of our present volition causes pain there is spiritual life. Happy sufferer, blessed torment, which stirs the blood of our soul to fresh endeavor! Sin-sorrows are the growing pains of the soul.

Evidently, then, no act can be a sin, though it may be a sinful act. Criminality may attach to an act the commission of which is not a sin.

To the objection that we have defined evil by denying it, the reply is that evil is truly evil to the sufferer, sin is truly sin to the sinner; but in the higher view, both are seen necessarily to belong to a general scheme the ends of which are good.

Perhaps the most fateful question remains to be asked. If we are all sinners, what are we to do about it? Must we continue to bear the burden of conscious sinfulness, or is there a way to be freed from it? We long with unspeakable desire to be free from three things: (1) our sins, (2) the sense of guilt, (3) the consequences. Almost all of religion is the outgrowth of this fersent desire. Who shall deliver us from the body of this death?

But stay: (1) all men are sinners and all inen will continue to be sinners; (2) all moral beings conscious of falling below their ideal of self-perfection will feel a sense of degradation (should they feel otherwise it would mean that moral growth had ceased); (3) the consequences of this failure, primarily, in so far as they are realized, are powerful motives toward a more strenuous 
endeavor to realize the ideal. The evils resulting to others are no part of our moral life except in so far as our realization of these evils affects our motives.

We come then to the unexpected result that sin, the sense of guilt, and the objective effects of sin are good instead of evil.

Distinguish between sin and the sinful act. The drunken man is guilty of no sin while committing the most shocking violations of the moral code, for he is irresponsible. With returning consciousness the enormity of his act produces a sense of guilt. In fact, he might be persuaded that he had committed crimes which had not been perpetrated at all and he would then feel all the remorse proper to the act.

The habitual indulgence in vice with no sense of guilt betrays moral death rather than sin, which was its author. On the other hand, if one sets up a false ideal, conscience may conduct a sensitive soul through purgatory for sins which seem to you or me but innocent pastimes.

But these reflections are ex cathedra and might be proper to a god-- or a philosopher. The important thing for us, as practical men, is that every sense of guilt is an added weight to the burden of responsibility. It lays another brick in the structure of character. Should the next occasion fail to elicit from us a more strenuous effort, guilt grows. Making of our dead ideals stepping stones to higher things is no empty poetic fancy. Sin is very real. Guilt is, and no logic can avoid it. Were we all-powerful, as philosopher's, we would not attempt to destroy it, but in our individual capacity our true self drives us to eternal conflict with this and all evil, and this conflict is the good.

But two attitudes are possible. The one finds us face to the front, undaunted, though defeated. There is perfect, unconquerable allegiance to the higher, larger self as it grows within us. The other attitude finds us either supinely fallen, helpless and hopeless, neglecting the ideal self, or wilfully combatting, while recognizing its demands. The world contains only saints and sinners. The change from one moral attitude to the other, whatever may be the accompanying machinery, is moral conversion. The attendant circumstances, such as the acceptance of some creed or the recognition of some savior, may be exalted above the essence of conversion. Great emotional convulsions or extatic visions may seem to be the prominent feature, but one 
may see visions and not be converted or be converted and not indulge in violent emotional contortions. Some, like the child who was exhorted to seek Jesus, may truthfully say, "I never lost him."

But our definition is not that exactly of theology. It would be sufficient to reply that theology is not now our topic, yet every man is religious and religion certainly ought to assist in right living which is also the object of ethics. We go back to our question. Is there any help other than a reluctant resignation to sin and to be sorry on the little plane of our individual endeavor?

It is not in the nature of the human soul to be content with a part where every part logically suggests a whole. The social soul recognizes the existence of a vast all-inclusive unit, the ideal whole of which it is a part. If every other being has claims upon me, then my entire, perfect allegiance is due to this absolute whole. We may conceive it as design, or will, or intellect, or we may clothe it with all of our own attributes carried up toward infinity as far as our imaginations can go. Every man, be he pantheist or deist, has his god. We may, with Margaret Fuller, call it "the universe." What do you suppose her "universe" looked like?

As students of psychological ethies this Absolute assumes the form of the greatest self - that perfection of attribute and fulness of action that means the fulfilment of all tendencies and the completion of all evolution. The fitness of self to form a part in that highest union becomes the eriterion of every act. The failure to realize or approach the ideal causes sharpest pain. Without this view of perfection progress would be impossible. The pull is from above. In terms of Christian theology, no man can come to the Son (the perfect exemplification of human perfection) unless the Father draw him. ${ }^{41}$

\footnotetext{
"I 'The term "pull from above" may require explanation. It may be objeeted that, when the largest possible self has been attained, it is eomposite, a mass of efforts of the individual. Are not our highest aspirations reflected as from a beaven of brass above us? Dirl any one ever prove to the satisfaction of the skeptie that prayer was ever objectively answered? The objection must be acepted for what it is worth.

When the indivdual sets up for himsolf an independent solf-existenec, the only proof he has of its validity grows out of the impossibility of thinking more than one universe. If our minds were not part and pareel of other activities and bound up with all other activities in one organism, then there woukl be no empulsion to aecept
} 
Again, the consciousness of repeated failure, the cumulative degradation of a life of sin, is fatal to successful conquest of new ideals. The load of past sin must be removed. Stripped of all refinements of technical phraseology, the purging of the individual ideal from those defects, the creation of the new self, this is the new birth and is likewise from above. Every sin reveals a discrepancy between the ideal self and the self of experience, and such sin casts a smirch upon the ideal which must be washed away before the will can act in view of the ideal perfection. The likeness of the perfect self must be set up afresh for each new effort.

the data of our mental activities as valid. Coherence is the criterion. Yet we are not going about denying our personal existence. So later, when the socius-ideas arise, we discover our experiences to be one with the generalized experience of society or "society-experience," i.e., we discover that all others also have certain feelings, susceptibilities, rights and responsibilities. All of this comes to us through our own experience and the validity of the society-experience rests on the same law of coherence. But no one will deny that we are influenced by society, even though we recognize that social influence must first be reflected in our individual socius-sense.

Finally, when we recognize the universality of laws, when we discover that we are part of a great universe which expresses a great movement or has a vast significance, even though we imperfectly understand it, and even though we may be as pagan as Marcus Aurelius, yet this recognition of the greatest of all realities is reflected back with great power into self. We say, "O Universe, I will as thou willest."

But, you say, this power is from within. In one sense, $Y e s$, but in a truer sense, No. It emanated from within, but it is reflected back with new power from without-from the truth we discover. It is a pull from above just as truly as the social impulses are pulls from without.

If this great meaning - this significant career or teleology of the universe be anthropomorphized and endowed with human attributes, it still is a response to human longing and its real proof is its power to cause reactions (regeneration) in the individual life and the philosophical consideration above stated that it is impossible for us to live in two universes. The going out on the part of our nature is indispensable; but, if there were nothing to respond to this going forth, there would be no "pull from above." A stone could experience no change of heart, but even the exploring dove must find land before it can bring back the olive branch of peace to the soul.

If humanity at large finds a response to its interpretive out-goings, it attempts a flight into the unknown. If it catches glimpses of design and recognizes that we are part of some destiny that embraces all, and if thereby mankind at large is helped

$$
\begin{aligned}
& \text { "Im ganzen, guten, schonen, } \\
& \text { Resolut zu leben," }
\end{aligned}
$$

as Goethe says, then the same law of congruousness or coherence that obliges us to believe in self and in society obliges us to recognize this greater reality and its "pull from above." 
So long as we find in the universe only a hostile array of antagonistic forces thrusting us down, our case may well seem hopeless. But, not so; even in the very sense of sin there is revealed the fact that there is a helping Hand let down. It is only in the limited view that nature is a "foe to grace;" the clearer eye will discern the fatherhood of God, the suggestion of forgiveness and the promise of ultimate success, where at first there only seemed a losing fight.

Forgiveness and regeneration appear, therefore, to be facts of ethical experience. Accepting the above view, we may admit with Bacon that

The world's a bubble and the life of man

Less than a span;

In his conception wretched, from the womb

So to the tomb;

Curst from his cradle and brought up to years

With cares and fears.

Who then to frail mortality shall trust

But limns on water, or but writes on dust.

But, however unlovely the units, when we contemplate them as organic parts of the majestic pageant of history, necessary stones in the temple of the omnipotent, they are clothed with the borrowed beauty of the completed whole.

How small a value does nature place upon the individual! Life is prodigal of its forces and wasteful of its products, but with what grim persistency does nature cling to its real gains. The new organ, once developed, reappears with mechanical infallibility and, even when rendered unnecessary by change of habitat, may remain for thousands of generations as a vestigial structure.

For it is not the individual but only the species, that nature cares for, and for the preservation of which she so earnestly strives, providing for it with the utmost prodigality through the vast surplus of the seed and the great strength of the generative impulse. The individual, on the contrary, neither has nor can have any value for nature; for her kingdom is infinite time and infinite space and, in these, infinite multiplicity of possible individuals. Thus nature naively expresses the great truth that only ideas, not individuals, have, properly speaking, reality, i. e., are the complete objectivity of the will. (Schopenhumer, The World as Will, Book IV.) 
But there is another side which is much more important for us practically. As expressed by Schopenhauer, the statement may be characterized as most misleading. Our individual lives are the concrete expressions of segments of the great dynamic unity of nature without which the manifestation of the energic idea we call species or genus would be but an empty abstraction; the reality of nature is made up of just these infinitesimal units of which nature seems so prodigal. The individual is a part and a necessary part of the sublime progressive revelation of the universe. If only a link, we are a necessary link in a chain as long as eternity and as strong as omnipotence. However small our isolated value, that value is affected by infinity as a coefficient.

Still farther, it will be seen that, reflexly, our conscious life is capable of being influenced by as much of the idea revealed in nature as we are able to receive. With our growing capacity, our contact with the infinite increases beyond assignable limits. It is not too much, therefore, to say that the value of the human soul is infinite and that the measure to which we realize this contact is the measure of our sympathy.

As Fisk says:

The Darwinian theory, perfectly understood, replaces as much teleology as it destroys. From the first dawning of life we see all things working together toward one mighty goal, the evolution of the most exalted spiritual qualities which characterize humanity. 


\section{THE SPIRITUAL PARADOX: A METAPHYSICAL STUDY OF IMMORTALITY}

He that findeth his life shall lose it.-Christ.

The cleaving to self is a perpetual dying.-Buddha.

During the past few years many questions once considered peculiarly pertinent to theology have come to be appropriated by philosophy, and students of the latter science do not hesitate to apply to the critical investigation of topics formerly considered wholly as matters of exegesis the methods and laws proper to metaphysics or even of psychology.

Among these topies is the general question of immortality. Foundations have been endowed for the express purpose of securing for the discussion of human immortality the services of the most eminent minds in diverse fields.

It is plain that the propriety of such study is wholly determined by its feasibility. The belief which one entertains respecting the future life may and often does, greatly influence his present life and the use which he attempts to make of daily opportunities. But at the present time the average individual possesses no opinion, though he may entertain a hope or be goaded by illdefined but haunting fears. It is commonly implied that no knowledge respecting that beyond the grave is possible and that faith is its legitimate substitute. As cautious a writer as Professor Paulsen says:

For it cannot be denied that this belief (in a future life) is becoming more and more unsettled in our times; and the future will hardly succeed in strengthening it.

On the other hand, it is plausibly argued that knowledge of the beyond might unfit us for the life that now is and that our eyes are holden in order that our short-sighted vision may be the better focused on daily duties and the lesser but necessary duties of the immediate future.

The fallacy of thinking and speaking of a future life in terms of our present limited sense-knowledge has given rise to extremely foolish 
visions of heaven, and made many gentle and religious minds incredulous.-Edwin Arnold.

But the fact that a conclusion is deemed impossible never yet acted as a deterrent to philosophical speculation; and, even if the main question must remain forever unanswered, there remains the possibility of a closer definition of its bearings. Nor is it altogether unprecedented that sufficiently close analysis of a question has set at rest the curiosity which asked it.

In the present case humanity finds itself in the position of a man who is awakened from sleep by the cry of "Fire" to the certainty of loss of his possessions and who must make instant choice of the precarious salvage of precipitate flight. Such choice as one makes in the emergency of our illustration is not more unpredictable or more irrational than the good the average human aspirant for immortality would select to take with him into the other world, if the selection were permitted to him. Witness the ideas of various peoples as to the nature of "heaven." It will, howevel", be very instructive and helpful toward further discussion to examine briefly the bare conception of immortality, and especially $u$ hat it is that should possess this property.

Perhaps the most immediate reply would be that people generally desire immortality each for his own self. Ordinarily it is not even felt to be necessary to inquire what this self is or what elements it contains, nor yet as to the completeness of its independence of others; but such inquiry is a necessary preliminary to any true conception of immortality.

When confronted with the phenomena of dissolution, the idea of the self which is a candidate for immortality is at once deprived of a large and important portion of the empirical self. The savage who is visited in dreams by his departed ancestor, while convinced of the reality of the apparition, is also forced to conclude that the vision lacks the corporeal presence of a living man and presents to our sense only a shadowy vestige of the bodily self once laid away in the grave or consumed upon the funeral pyre. So the consensus of humanity is that the inviolable self is spiritual; and even though this spirit be endowed with the power of assimilating to itself a body such as may be suited to the sphere within which it resides, yet, at any rate, the body which now clothes myself is of the earth earthy. 
Thus early in our search we are brought face to face with the evasive problem of the relation between body and soul. Postponing this question for the present and simply admitting that our flesh and blood cannot inherit eternal life and must be left behind along with our lands and our gold, let us ask ourselves seriously for what do we desire perpetuity. Naturally they will be things which we most prize here. Sense-gratifications, appetites and passion we must be content to resign; and, if experience has been of the average sort, we may console ourselves by the thought that with such resignation we also escape the harrassing wear and tear, the pains and myriad woes incident to bodily existence. In all deseriptions of the other world it is almost surprising to note that emphasis is very strong on the negative advantages-advantages which would accrue equally in the case of annihilation. There will be no more tears and no more pain over there.

But, positively, there operates the great vital law of self-preservation. We shudder at the thought of losing our identitywe cannot bear to think of being blotted out. True the daily experience of temporary annihilation has been clothed by poetry with all the honeyed praise of which language is capable - "nature's sweet restorer, balmy slcep." A very little reflection, however, will show that this instinctive love of life, as a product of natural selection, refers to the physical existence and only by a sort of analogy is made to apply to the soul.

To the young life presents itself as a career, not as a possession; there are joys to experience, victories to gain, achievements to attain, and all by virtue of the powers springing in the life of the present as the seed of the life yet to be. To think of the loss or curtailment of this career, the birthright of all men, is inexpressibly terrible. Even the mourner over the too early dead finds in the abridgment of a promising eareer the most poignant oecasion of grief. The idea that the apparent destiny of the human career is thwarted by death is a most common and potent argument for belief in immortality. It is inconeeivable, we say, that nature or God should permit such preparations to be wasted or such promises to be disappointed. Somehow, somewhere, these prophesies are fulfilled and the sun that here has its setting will certainly rise in undimmed glory elsewhere.

To the man in middle life, who has witnessed the failure of so many individual plans and the futility of individual hopes, life 
becomes more and more the annex of some "cause." There are perennial things which endure and bear fruit year by year while death reaps its frequent harvests of brief human life. The individual life becomes of value chiefly as a factor in some such powerful instrument for the betterment of collective humanity.

Finally, when the forces of life are so far spent that one's participation in the "cause" becomes insignificant and the enjoyments of life cease to lure to linger in paths which no longer please, the instinct of self-preservation grows less assertive and the fear of the death agony perhaps yields to evidence like that of Dr. Hunter who, in his latest moments, "grieved that he could not write how easy and delightful it is to die." Still the thought of individuality, if it no longer affrights us or menaces with the loss of good naturally our right, appears a solemn and melancholy possibility, repellent to our feelings. Memory supplies what hope no longer affords, and it seems incredible that we who have formed so large a part in worthy undertakings should perish while the impress of our lives, by a spiritual law of conservation of energy, continues forever.

Of the kind of immortality implied in the perpetuity of effort when once exerted, there seems to be no doubt. We are intellectually convinced that our influence is immortal; but, like Kutadanta, the disciple of Buddha, we care little for any other immortality but that of the individual self. Nor does the statement of the Buddha that "he who cleaves to self must pass through the endless migrations of death, he is constantly dying; for the nature of self is a perpetual death," nor yet the word of a greater than Buddha that "he who would save his life shall lose it" cause us to subdue the craving for an immortal life in which there may be continued the memories and experiences of our present individual self.

The attribute of individuality is one which gives, and since the time of Aristotle, has given the logicians much uneasiness. In the Ingersoll lecture for 1899 , Prof. Josiah Royce, in the course of a discussion of "The Conception of Immortality" devoted practically the sum of his endeavor to the settlement of this vexed question, rightly judging it to be a necessary preliminary to the broader theme. 


\section{Professor Royce states that}

"our human type of knowledge never shows us existent individuals as being truly individual. Sense, taken by itself, shows us merely sense qualities-colors, sounds, odors, tastes. These are general characters. Abstract thinking defines for us types." "Even if by comparisons and discriminations we had found how one being appears to differ from all other now existent beings, we should not yet have seen what it is that distinguishes each individual being from all possible beings. Yet such a difference from all possible beings is presupposed when you talk, for instance, of your own individuality." "For I must still insist,- - not even in case of our most trusted friends,-not even after years of closest intimacy, - no, not even in the instance of Being that lies nearest to each one of us, - not even in the consciousness that each one has of his own Self,--can we men as we now are either define in thought or find directly presented in our experience (italics mine) the individual beings whom we most of all love and trust, or most of all presuppose and regard, as somehow certainly real. For even within the circle of your closest intimacies our former rule holds true, that, if you attempt to define by your thought the unique, it transforms itself into an unsatisfactory abstraction,- a type and not a person,-a mere fashion of possible existence that might as well be shared by a legion as confined to the case of a single being."

If one were limited to the abstract and objective logic or were to attempt the problem simply as a speculative attempt to form individuals out of algebraic combinations of qualities, this would be true. But it is far otherwise when we turn to what is "directly presented by our experience." The fallacy of Dr. Royce's entire discussion crops out finally, as we conceive, in his definition of reality. The conclusion is that "you must define the whole Reality of things in terms of Purpose." Accordingly individuality is a conception expressible only in terms of satisfied will. "An individual is a being that adequately expresses a purpose."

Such limitation as this would imply that a sense of reality is possible only after a complicated process of ratiocination quite out of the question in most eases. We wonder whether the mother is not a "real being" and an "individual" to her babe. As a matter of fact, reality and with it individuality are among the first attributes consistent with mentality. We may insist that our concept of individuals does not wait on a philosophical analysis of teleology. Nor are we denying that in Dr. Royce's statement there is an important element of truth. When we as philosophers begin to seek the last ground of validity and to drive skepticism into its last ditch, that arch enemy of philosophy is drivenout only by the recognition of a teleology or coherence in an organized 
universe; but this is not how we come by realities. No skepticism ever makes a "real" any less real, nor does philosophical investigation make it more real. Nor is this statement to be dismissed as a psychological generalization out of place in metaphysics. Reality we have defined as affirmation of attribute. It implies the union of objective and subjective. The philosophical concept of Pure Being we can think of apart from a subject; but reality is a realizing, it is dynamic. We may think of the abstraction "shining" apart from the light that shines, but the light is the shining.

In this process (of realizing) a limitation of the pure spontaneity of being is implied and this produces individuality. What produces the individuality of the subject no one can saythe eye may not view itself-but certain it is that, the subject being what it is, the world can and must present itself only as a succession of individuals. Dr. Royce finds it impossible for the most gifted lover to explain why the object of his affection is unique among women; for he is able to express the height of her individual perfections, which makes her all the world to him, in no other terms than those which all other lovers use. But Touchstone had no such difficulty with his Audrey, when he introduced her as "an ill-favored thing, sir, but mine own." In a moment of candor the supposed lover might admit that some other maid might have all the charms of his Helen (he is frequently forced to hear that "there are fish as good in the sea as have ever been caught") but he is undisturbed, she is "his own." In other words, the essence of individuality lies in relation to the subject. The lover finds the uniqueness of his inamorata in the relation she sustains to him. We distinguish objects as individual because of relations between such objects and ourselves. There may be a thousand peas exactly alike, but this particular pea is in my shoe, and is a very particular and individual pea. Any other pea might be there; but, by virtue of its immediate assailment of consciousness, this pea is individualized. I realize its presence. No amount of philosophical speculation as to the lack of individualizing properties will prove convincing so long as the relation of this pea to my "immediate experience" remains what it is. The discovery of some particular fleck of color upon one out of a thousand leaves would not, as Dr. Royce shows, make of it an individual; for at any moment we might find its duplicate, 
but the commonest kind of leaf now seen becomes "mine own" and a unique leaf thereby. I may thrust my cup a thousand times into the ocean and each cupful of water will be an individual till it flows back into the immensity of the infinite.

The ultimate criterion of validity is, we repeat, congruousness. We must believe that the world is an organism or we cannot begin to think, and so, as philosophers, we admit that individuals which are creatures of our experience must have an external validity; but how we are to construe the relations which are perceived as individual is a large question. It is easy to learn that the objects which we perceive as discrete lose this discreteness when we learn more about them. Their relations to us are but insignificant as compared to the relations they sustain to the universe at large. The present is but a drop when seen in relation to past and future -in fact when so compared, it is not. Individuality is dependent upon the now; but there is no now, only a forever.

So far from the purpose creating the individual as we know it in experience, it destroys it by converting it into continuous quantity. You cannot photograph the movement of the trainindividuality is an instantaneous photograph, while purpose is the train conceived in motion; it is a trajectory. But, it is asked, Could you not trace out the single thread in the tangled skein and would not the thread, though endless, be an individual? The illustration is faulty; for really the continuity of the thread is as much lateral as longitudinal, except that we fail to perceive the lateral connections. Strict analysis might follow the lines of force in the stream passing over Niagara, though each particle is under equal pressure at all times in all directions from its adjacent portions of the stream. In this sense purpose does individualize. It serves to express the share of one part of the universe in its total purpose. Here, as before, it is an analysis imposed from the mind instead of something inherently individual.

Individuality thus appears as a limitation. We cannot conceive of existence without it, but "Where wast thou when I laid the foundation of the earth?" "Knowest thou the ordinances of heaven?" Perhaps there are things not dreamed of in our philosophy, and it may yet be true that it hath not entered into the heart of man to conceive of many things the truth of which we have no right to deny. Beeause our conseionsness requires individualizing as a condition of its functioning, it does 
not follow that consciousness might not exist in forms not requiring such limitation.

But the self which we sought to preserve would seem to have disappeared with other forms of individuality under strict metaphysical inquiry. To get at this matter in a different way, let us consider what self is. In your case and mine, what self do we wish to take into the other world; that which was our self at ten, at twenty or at sixty years? It is not the decrepit body, ready to welcome the grave, not yet is it the immature and illbalanced self of early youth. Is there any moment of life of which we can say this is the stage which we desire to perpetuate to all eternity? Evidently there is no such stage. We think rather of the ideal self--what we dream we might be if permitted to outlive the effects of our follies and to realize the best without suffering the worst of our experience. A purified spirit in a glorified body is what we crave, but this is not immortality, it is reincarnation.

Very suggestive and illuminating is the discussion of identity and non-identity attributed to the Buddha (see Carus, Gospel of Buddha, chap. LIII). By the parable of the lights the futility of defining individuality is well illustrated. The Buddha says:

"Self is death and truth is life. The cleaving to self is a perpetual dying, while moving in the truth is partaking of Nirvana, which is life everlasting." "Thy self to which thou cleavest is a constant change. Years ago thou wast a babe; then thou wast a boy; then a youth, and now a man. . . . Now which is the true self, that of yesterday, that of today, or that of tomorrow, for the preservation of which thou dost clamor. . . ." "Practice the truth that thy brother is the same as thou. Walk in the noble path of righteousness and thou wilt understand that while there is death in self, there is.immortality in truth."

The two greatest teachers of religious truth, the Buddha and the Christ, in whose doctrines (shorn of what is obviously local color) the essential agreement is so unmistakable as greatly to enhance their intrinsic influence, earnestly strove to minimize the concept of individual immortality in the crude form in which it was entertained by their followers. The greater success of the Buddha in this direction is to be ascribed to the more favorable soil upon which his teaching fell and not to the greater purity of his doctrine. It was inevitable that the teaching of Jesus 
should be distorted to the support of the complicated beliefs of the Jewish doctrinaires in stages and grades of future existence into which much of the grossness of this life was transported. Sidartha, on the other hand, had but a sect as it were of the Sadducees for his propagandists - men accustomed by contemplation to distinguish the real under the phenomenal.

Christ warns that in the other world men neither marry nor are given in marriage; that they do not seek emoluments or high stations, but are like the heavenly influences or "Angels of God;" and, while using every vehicle of expression and illustration to convey the idea of superior felicity of the other world, clearly teaches that this felicity in some way consists in oneness with God. He informs his disciples of a great gulf fixed between the other world and this, and it is legitimate to conclude that this gulf is a natural result of the extreme divergence of the two stages of existence. Far different the teaching of the Church, which carries the extreme of individuality characteristic of its relations in this life into the next world with little change. This tendency of the teachers of religion and its poets illustrates the desire for an immortality of earthy consciousness and associations.

Assuming that immortality must be of this sort, viz: a perpetuation of our soul as the thinking, remembering, and feeling function of self, Prof. William James attempts, in his Ingersoll lecture for 1897, to remove two important objections to such belief.

The first objection grows out of the psycho-physiological dictum that thought is a function of the brain. This is again the body-mind problem which we at first agreed to waive for a time.

But let us see how a representative psychologist meets this issue. In his own words:

I must show you that the fatal consequence is not coercive, as is commonly imagined; and that, even though our soul's life (as here below it is revealed to us) may be in literal strietness the function of a brain that perishes; yet it is not at all impossible, but on the contrary quite possible, that the life may continue when the brain is deatl.

The supposed impossibility of its continuing comes from too superficial a look at the admitted fact of functional dependence. But there are other kinds of function besides productive or generative functions, there are transmissive functions. 
When we think of the law that thought is a function of the brain, we are not required to think of productive function only; we are entitled also to consider permissive or transmissive function.

Our brains may be transparent spots in the surface veil of phenomena, hiding and keeping back the world of genuine realities. The brain might be an independent variable, the mind would vary with it.

Consciousness does not have to be generated de novo in a vast number of places. It exists already, behind the scenes coeval with the world.

One argument which seems to have more weight with Professor James than he may care to admit, is the supposed value of such a theory in explaining or permitting a belief in the occult, to which he stands committed. This theory is like the Swedenborgian idea of "influx" and may be acceptable in theological circles as consistent with the activities of "The Spirit." The question here is whether the theory is consistent with itself.

Let us examine it more closely. Consciousness is assumed as coeval with the world. Consciousness is, let us say, somehow a product or rather a general mode of all energy or, at least, of universal energy. But this state of complete spontaneity or universality cannot be assumed to have any specific consciousness until limitations are imposed upon it. This limitation must be from within or from without. If universal energy be restrained from without, there is other energy not comprised in the universal energy and we are confronted by the logical fallacy of a divided universe. The limitation is then a self-limitation and consequently teleological.

The existence of modes of consciousness results from the limitations of energy which thus in certain specific forms manifests itself as sensations and the like-in short, in thought. If the brain is the name given to the sum of the limiting conditions or determinants of energy by which modes of consciousness arise, then the brain produces thought just as truly as anything can be produced. It is not permissive or transmissive in the sense that sundry thoughts exist behind the veil and some of these filter through, but it acts in the sense that the water-wheel generates forces. It does not create energy but it does create the mode of energy. Creation is, after all, but the self-limitation of energy. 
Still, this form of expression is also more or less misleading. What we call the brain is as truly a phenomenon of experience as what we call mind,- - only a step farther removed, and it accords better with the facts to consider both as correlative expressions of energic forms (life) which reveals itself in various modes, though to our direct apprehension it only reveals itself as psychic acts or modes.

Applying the necessary corrective to Professor James' theory, it appears that no gain is secured, for the kind of immortality which we crave and he proposes is not that of undifferentiated energy back of the brain and the mind but that of the modes determined, as he would say, by the brain. The naïve assurance that the brain is only a thin spot that lets consciousness through fails; for, certainly, the size and position of this thin spot must have all to do with the kinds of modes of energy involved in thought. One would not say that the shape of the orifice had nothing to do with the generating of specific energy by a turbine, for example. Otherwise, if thoughts are ready made and are in no wise determined by the brain, why do we have one? The argument is an ingenious non sequitur.

But with the modification that brain and thought are simultaneous expressions of life, $i$. e., an organized self-limited form of energy having a teleological ground and a career expressed in its form, we discover two series of variables whose tie is their common relation to an existence of which they are more correctly described as appearances. From the series of thought-variables we may, by experience, learn to predict the brain-variations and vice versa; but it does not follow that brain-processes cause thought-processes. Lest we should be prematurely drawn into a discussion of eausation, from which pit escape is well-nigh impossible, we may hasten to admit that causation in this sphere must be identified with coherence in a system or organism, and so becomes an aspect of teleology as in natural science it is but one form of statement of the law of conservation of energy.

But whatever be the nature of the being constituting the basis of coherence, of brain and mind, it is subject to change; thought in a connected series bound together by memory into a unitary experience or personality is not apparently necessarily continuous. Life may go on in its absence for a time. Not every kind of brain-process is continually functioning. In some sense life 
which we now live has descended to us from our ancestors. Such significance as our life has for the universe is not limited to either a conscious continuum or a brain continuum. The perishing of our body may render the presumption so high as to resemble a certainty that the forms of conscious existence we now have shall cease with it, but the vanishing of these by no means proves that the teleological unit which formed the ground for these appearances has been destroyed. As well might the chemist whose knowledge is limited to what he can see deny that water exists in the gaseous state because he can no longer discover it. It can hardly be assumed that so complex and important a center of force as a man leaves no trace besides those we experience, and has no properties besides those we have discovered. The utter destruction of the life back of the phenomenal is inherently very improbable from a purely scientific point of view. Without arrogance man can claim that his advent into the world has changed the whole character of the universe. If those centers of energy which we (in our ignorance) call molecules of matter have such a high degree of persistence as to give rise to a theory of imperishability of matter-in so much that these molecules will pass through all the mutations of experimental treatment we can give them and through numerous phases and clemical compositions - it were strange indeed if the unit, "man," should be so unstable that a breath would annihilate him. An heavenly alchemy may indeed change him from one state to another as the ice passes into the clouds, but is still water.

"But" breaks in some impatient listener, "this is beside the point; what we want to know is, shall we know our friends over there?" As James says, what we all wish to keep is just these individual restrictions, these self-same tendencies and peculiarities that define us to ourselves and constitute our identity, so-called. Our finiteness and limitations seem to be our personal essence; and when the finiting organ drops away, and our severed spirits revert to their original source and assume their unrestricted condition, will they be anything like the sweet streams of feeling which we know, and which even now our brains are sifting out from the great reservoir for our enjoyment here below.

The only answer given is by way of suggestion: "It might prove that the loss of some of the particular determinations which the brain imposes would not appear a matter for such absolute 
regret." With this suggestion we too may, for the present, rest content.

The second obstacle discussed by Professor James is merely that growing out of the overpopulation of the universe in event of general immortality; but this is no longer a difficulty, if the results of the foregoing discussion are accepted, even if we go to the full length indicated by the following passage from Edwin Arnold's "Death-and After:" "If the Bathybius-nay, even if the trees and the mosses, - are not, as to that which makes them individual, undying, man will never be." But, in general, we may say with the author last quoted, "we have to think in terms of earthexperience, as we have to breathe in terms of earth-envelope. We ought to be reassured rather than disconcerted by the fact that nobody ean pretend to understand and depict any future life, for it would prove sorely inadequate if it were at present intelligible."

Our conclusion, drawn from a purely metaphysical consideration is not at variance with that expressed by Paulsen, in his Ethics. "The temporal life is the phenomenal form of a life which is eternal as such." To the objection above urged that one does not care for an existence without consciousness, Paulsen replies:

Well, who says that reality is without consciousness? May not the All-Real have an absolute consciousness of itself, of its essence?

And who will claim that individual beings, who have a temporal consciousness, could not have an eternal consciousness.

To this we may add that so far as we know the possibility of reality in a strict sense is bound up with that of consciousness.

The practical consequences of such a view as that to which we seem driven by purely metaphysical considerations may detain us for a parting word. Our life we find is not a possession, but a eareer. It consisteth not in the abundance of what one possesseth. It is more than meat, $i . e .$, it is more permanent than the sensuous joys which it affords. If we may believe that the little segment we can foresee on the earth may determine the direction of the future course of an eternal life, as the aim of the gun determines the angle of trajectory of the missile, it becomes a matter of transcendent interest to see that the aim is right, if we only can be convinced by any means that we have anything to do about it. For him who does not care to enter the mazes of ethical 
theory it may suffice to remember that the universal beliefs of humanity always have some justification. As Paulsen says:

The time will come, even though not until you are on your death-bed, when one thing alone will be material to you: whether you have honestly done your work in this world, however great or small it may have been, as a righteous man; whether you have fought the battle of life as a brave and faithful soldier.

We may differ from this author in thinking that we shall not be indifferent to whether we have tasted joy and sorrow here below and may believe that we should rejoice to enter as fully as possible into the range of human experience; we may remember thankfully our victories and rejoice that we have dipped into the sea of knowledge. For is not this segment, albeit small, a real part of the whole life we are living? We may not sympathize with those who would have us depreciate the good which nature so carefully purveys for us here; but, still, it will ever be of vastly greater importance to us to feel that we have neglected no preeaution so to direct our bark that, when it passes out into the night, it shall not depart from its destined course nor miss of attaining the harbor of a blessed immortality. 


\section{ETHICAL CONCLUSIONS}

Ethical living passes through three stages, the individual, the social and the religious. These are not mutually exclusive but represent the form of the summum bonum most efficacious in each.

In the individual stage natural selection is the determinant and self-preservation is the motive. Acts are good or bad as they tend to conserve the individual existence or fail to do so. Selfconsciousness emerges from the animal consciousness clothed with the armor of protective instincts and impulses derived from natural selection.

In the social stage conscious selection is the determinant and social development is the motive. Self has enlarged by continual accretions of mine to me. Family, clan, country and the great round world, successively fall under the conquest of the victorious self. Self-renunciation as the supreme act of selfishness becomes the way to the summum bonum or the highest good of my universe. Acts are right or wrong as they serve society or not.

In the religious stage the divine will is the determinant and self-absorption in the deity is the motive. Man becomes conscious of self as part of a universal system. He feels participation in the divine plan. He not only thinks God's thoughts after him but he wills his acts with him. "Thy will be done" becomes his supreme desire. Nature and humanity become of one family with me, not because thay are mine but because they are God's and I am God's. Sympathy is universal. Sin is no longer rebellion, it is treason. To love God is joy and to love God is to love all created things, because we sec as he sees. We have participated in creation as it was and is and shall be revealed. Nirvana ${ }^{42}$ begins on earth. The kingdom of heaven is within you. Acts are not good or bad, right or wrong, but loyal or disloyal as they conform to the suprema lex, the will of God, or fail to do so.

${ }^{42}$ The Buddhist conception of Nirvana is in one passage interpreted ly P'rofesoor Herrick in these words: Nirvana is deliverance from avil. It is not a heaven of golden streets; it is not annihilation; but it is a state of unmixed satisfaction; it is permanence as contrasted with present fluctuations. 



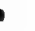



THE UNIVERSITY LIBRARY

This book is DUE on the last date stamped below Alk 9 1968

उदC 281982

Form L-9-15m-2,'36

UNALKSITY Of CALIFORNLA

A'T

LOS ANGELES

LIBRARY 


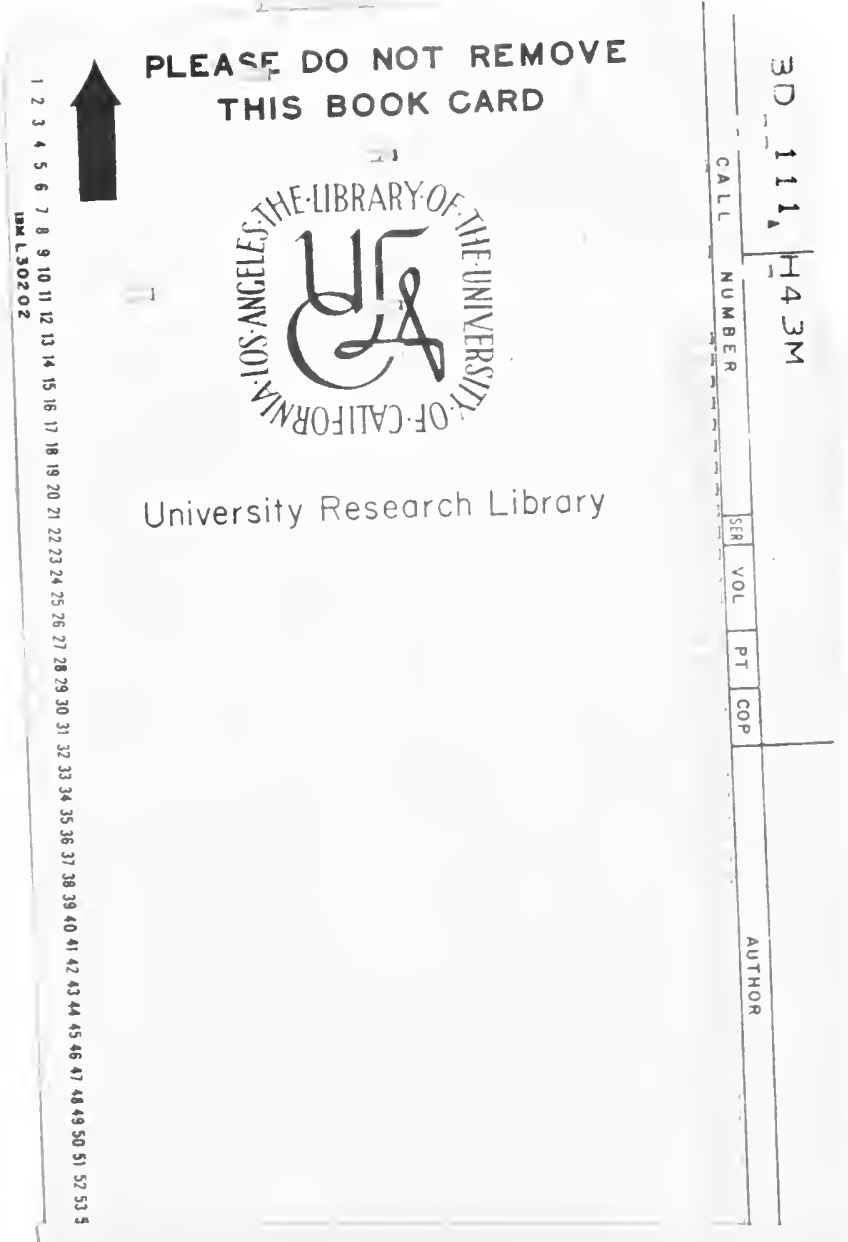


